\title{
Children's Evaluation of Information on Physical and Biological Phenomena: The Roles of Intuition and Explanation
}

\author{
Hye Ryung $\mathrm{An}^{1}$, Naya $\mathrm{Choi}^{2}$ \\ Ph. D., Department of Child Development and Family Studies, Seoul National University, Seoul, Korea ${ }^{1}$ \\ Associate Professor, Department of Child Development and Family Studies, Seoul National University, Seoul, Korea ${ }^{2}$ \\ 정보의 직관부합성과 설명의 유형에 따른 유아의 정보 평가: \\ 물리·생물 현상에 대한 정보의 타당성 \\ 안혜령 ${ }^{1}$ 최나야 ${ }^{2}$ \\ 서울대학교 아동가족학과 박사 ${ }^{1}$, 서울대학교 아동가족학과 부교수 ${ }^{2}$
}

Objectives: This study aimed to investigate whether children's evaluation of information provided by an informant differs depending on the intuitiveness of the information provided, the presence of and types of additional explanations, and the age of the child.

Methods: The participants were 158 children, aged 4 to 5 years, from eight child-care centers located in Seoul and Gyeonggi Province. Each child was interviewed individually, after completing a pre-test for measures of language comprehension.

Results: First, when the informant provided information on physical and biological phenomena, children were more likely to evaluate intuitive information as plausible, compared to counterintuitive information. In addition, 5-year-olds were less likely than 4-year-olds to evaluate counterintuitive information as plausible. Second, after an explanation was added, children were more likely to evaluate counterintuitive information as plausible, when this explanation was causal rather than descriptive or circular. Third, the addition of an explanation was likely to result in the evaluation of intuitive information as less plausible, and counterintuitive information as more plausible.

Conclusion: Based on children's evaluation of information about physical and biological phenomena presented to them, this study confirmed that 4- and 5-year-old children were able to independently evaluate the plausibility of information, depending on the intuitiveness of the information, and the presence of and types of explanations. It also revealed that with increasing age, children become more skeptical about the plausibility of counterintuitive information, and demonstrated epistemic vigilance even when presented with intuitive information with an explanation.

Keywords: evaluation of information, intuitiveness of information, types of explanation, plausibility of information, physical and biological phenomena

\section{Introduction}

유아는 주변을 자발적으로 탐색하며 지식을 구성해나가는 동

Corresponding Author: Naya Choi, Associate Professor, Department of Child Development \& Family Studies, Seoul National University, 1 Gwanak-ro, Gwanak-gu, Seoul, Korea

E-mail: choinaya@snu.ac.kr
시에 다른 사람이 전달한 정보를 통해서도 배워나가는 존재이 다. 어린 유아도 언어를 통해 타인과 정보를 나누고(Bohannon \& Bonvilian, 1997; M. Y. Sung, Chang, \& Chang, 2016), 자신의

(C)The Korean Association of Child Studies

This is an Open Access article distributed under the terms of the Creative Commons Attribution Non-Commercial License (http:// creativecommons.org/licenses/by-nc/4.0) which permits unrestricted noncommercial use, distribution, and reproduction in any medium, provided the original work is properly cited. 
호기심이나 요구를 충족시켜줄 정보를 스스로 구한다(Frazier, Gelman, \& Wellman, 2009; Kurkul \& Corriveau, 2018). 유아는 정보를 통해 현재의 문제를 해결할 뿐 아니라 기존의 지식을 수정하고 새로운 지식을 형성할 자극과 기회를 얻는다(Harris, 2012; Walker, Lombrozo, Williams, Rafferty, \& Gopnik, 2017).

그러나 다른 사람들과의 교류를 통해 얻은 정보가 모두 좋 은 정보일 수는 없다. 의도적인 속임의 문제를 떠나서도 정보 제공자의 지식이나 인식 수준, 부정확한 전달, 실수 등의 이유 로 잘못된 정보에 노출될 가능성은 유아에게도 늘 존재한다 (Jaswal \& Kondrad, 2016; Mills, 2013). 정보의 무분별한 수용 은 잘못된 판단과 행동으로 이어져 위험을 야기할 수도 있으 며, 정보의 혜택을 온전히 누리지 못하게 한다. 그러므로 유아 가 자신에게 필요하고 좋은 정보를 얻는 능력과 더불어 잘못 된 정보나 질이 낮은 정보를 체계적으로 경계하는 능력을 길 러나가는 일은 필수적이다. 또한 유아가 정보를 어떻게 평가 하는지는 정보에 대한 태도를 형성하며, 나아가 정보를 어떻 게 받아들일지에 대한 결정과 그로 인한 학습과 발달로 이어 질 수 있다(Harris, Koenig, Corriveau, \& Jaswal, 2018; Sperber et al., 2010). 따라서 유아가 정보를 지식으로 획득하기까지 과정 에 평가라는 사유의 과정을 통해 어떻게 개입하는지 밝히는 것은 발달적 관점에서 매우 중요하다.

유아가 타인이 말로 전달한 정보가 그럴듯한지 스스로 판 별하는 과정과 그에 대한 발달적 변화가 어떻게 달성될지에 의문이 발생한다. 그러나 오래 전부터 여러 학문적 관점에 서는 유아는 '잘 믿는 특성을 가진 존재'라는 인식이 있었다 (Couillard \& Woodward, 1999; Dawkins \& Krebs, 1978). 특히 3 세경의 유아는 4 세 이상의 유아와 비교할 때 성인이 말로 전 달하는 정보를 꽤 잘 따르며, 자신의 신념이 있을 경우에도 정 보제공자의 잘못된 주장에 대한 신뢰를 오래 유지하기도 한 다(Jaswal, 2004, 2010; Jaswal, Croft, Setia, \& Cole, 2010). 타인 의 정보에 대한 유아의 신뢰와 평가에 관심을 둔 연구들 중에 는 앞의 결과에서와 같이 잘 믿는 성향을 지지하는 입장과 어 린 연령에서도 믿을 만한 정보를 분별하고 그 질을 평가할 수 있다고 보는 입장(Harris \& Corriveau, 2011; Koenig \& Harris, 2005; Sperber et al., 2010)이 엇갈려 왔다.

최근에는 타인이 말로 전달하는 정보의 출처나 내용을 의심하며 비판적인 관점에서 평가하는 초보적인 능력의 존 재와 발달에 대해 학자들의 관심이 높아지고 있다(Y. Choi, 2016; Harris et al., 2018; Heyman, 2008; Mills, 2013). 이들은 개인에게 잘못된 정보를 얻을 위험을 막기 위해 마련된 '인 식론적 경계(epistemic vigilance)'라는 인지기제가 있다고 보
기도 하고(Sperber et al., 2010), 정보 평가의 발달을 '회의주의 (skepticism)'의 발달이라 설명하기도 하였다(Heyman, $\mathrm{Fu}, \&$ Lee, 2007; Mills \& Elashi, 2014). 이들은 유아기에서부터 나름 의 기준으로 정보를 평가할 수 있다고 할 때 어떤 단서와 자원 을 사용하는지를 밝히는 데 관심을 두었다.

정보 평가의 과정은 크게 정보의 출처인 정보제공자의 신뢰 성(trustworthiness)에 대한 것과 정보 내용의 그럴듯함, 즉 타당 성(plausibility)에 대한 것으로 구분된다(Bascandziev \& Harris, 2016). 그동안의 유아 대상 연구들은 정보제공자의 신뢰성에 주 로 초점을 두고, 정보제공자의 특성에 기초하여 믿어야 할 사 람과 믿지 말아야 할 사람을 구분하는지를 알아보았다(Harris \& Corriveau, 2011; Koenig \& Harris, 2005). 그런데 유아가 가장 빈번하게 의사소통하는 성인은 부모와 교사이며(Chouinard, 2007; Gil \& Park, 2013; E. Y. Sung, Kim, \& Yoo, 2011), 유아는 자 신에게 긍정적인 영향을 미치려는 사람들에게서 많은 정보를 얻는다. 누가 믿을만한 정보제공자인지 구분하는 것만큼 믿을 만한 사람이 전달한 정보의 타당성을 살피는 능력도 유아에게 요구된다. 누가 더 나은 정보를 제공하고 있는지 구별하기 위해 서로 경쟁하는 특성들을 비교하는 것이 아니라 한 명의 정보제 공자가 전달한 정보를 탐색하는 일은 말에 담긴, 현저하지 않은 속성에 집중해야 하므로 상대적으로 더 어려운 과업일 수 있다. 아직 유아의 정보 타당성 평가에 대해 밝혀진 바가 적지만, 점 차 관심이 높아지고 있다(Lane \& Harris, 2015).

유아가 정보가 그럴듯한지를 평가할 때 활용하는 정보의 특성을 실증적으로 규명한 경우는 아직 드문 편이나, 직관 (intuition)이나 관습적 지식에 부합하는지 여부, 주장성, 논 리 등이 단서로 활용된다고 논의된다(Bascandziev \& Harris, 2016). 먼저, 정보가 직관에 부합하는지 여부가 대표적인 단서 로 꼽힌다(Harris et al., 2018; Lane \& Harris, 2015). 직관은 세상 에 대한 가장 기초적인 지각 방식이라는 의미를 가지며(Jung, 1971), 특히 유아기는 직관에 토대를 두고 세상을 바라보는 시 기라 본다(Piaget, 1929). 이중처리이론(dual-process theory)을 통해 인간의 인지과정이 성인에게 있어서도 분명하게 구분되 는 두 체계로 이루어진다는 점을 제시한 학자들(Epstein, 1994; Evans, 2008, 2010, 2011; Hogarth, 2001)은 직관이 추론을 통 해 이루어지는 반영적인 처리 과정과 대립되는 특성이라고 간 주하였다. 그리고 직관에 기초한 사고가 인지적인 노력을 기 울이거나 작업기억 용량을 할애할 필요 없이 정보를 즉각적 이고 자동적으로 처리해준다고 보았다. 한편, 직관은 이론이 론(theory theory; Gelman, 2000; Spelke, 2000)의 핵심지식(core knowledge) 개념과도 유사성을 가지는데 이 때 핵심지식은 과 
학적인 지식과는 다르며 유아가 세상을 이해하는 기초 틀로 간주된다(Wellman \& Gelman, 1998). 즉, 유아는 생존과 생활 을 위해 필수적인 영역의 초보적인 지식들을 기초 신념이자 직관의 형태로 가지며, 이것에 우선적인 토대를 두고 외부에 서 들어오는 정보를 빠르게 파악한다.

주요 영역에 있어 다양한 직관들은 영아기를 거쳐 초기 유 아기에 이르기까지 일찍 형성된다. 그 중 물리 영역의 직관 은 주로 물리적 대상의 고유한 특성이나 물리 현상과 관련되 며, 대상의 영속성과 시공간적 연속성, 고체의 견고성, 중력이 나 관성 혹은 물리적 힘에 의한 물체의 움직임이나 형태 변화 등에 대한 직관이 영아기에 형성된다(Baillargeon, 1986, 1994; Spelke, 1994; Spelke, Breinlinger, Macomber, \& Jacobson, 1992). 그리고 생물 영역의 직관은 주로 생물의 고유한 특성 또는 그 들의 생존과 성장의 기반을 이루는 생물 현상과 관련되며, 동 물의 성장원리로서의 방향성, 번식과 단계적 순서, 섭취에 따 른 성장과 활력의 생성, 신체 형태에 따른 운동적 특성, 신체 의 부분과 생존이나 생활의 고유 기능 수행 등에 대한 직관 이 비교적 이른 시기에 형성된다(Carey, 1985; Gelman, 2000; Gelman, Spelke, \& Meck, 1983; Inagaki \& Hatano, 1996, 2006; Jones, Smith, \& Landau, 1991; Keil, 1995; Rosengren, Gelman, Kalish, \& McCormick, 1991). 이에 따라 유아는 잡고 있던 물 체를 놓으면 아래로 떨어질 것이라 여기고 다른 것으로 지지 하면 떨어지지 않을 것이라 예상한다(Baillargeon, 1986, 1994; Spelke, 1994). 또한 생명성의 인식을 식물이 아닌 동물에 대해 서 더 빨리 습득하며(Inagaki \& Hatano, 1996, 2006), 초기 유아 기에도 동물이 성장이나 섭취와 같은 생물학적 속성을 가진다 는 점을 인식하고 특히 성장이 무작위하게 일어나지 않을 것 이라는 기대를 가진다(Carey, 1985; Keil, 1995; Rosengren et al., 1991). 본 연구에서는 정보가 직관에 부합하는지 여부에 따라 유아의 정보 평가에 차이가 있는지를 살펴보기 위해 유아기 에 분명하게 형성하고 있다고 보는 물리.생물 영역의 직관을 활용하고자 한다. 유아의 주변에서 흔히 일어나는 물리.생물 현상은 행위주체로 인간, 동물, 물체를 두루 가지며(Wellman, Hickling, \& Schult, 1997), 그 발생이 비교적 넓은 범위에 적용 된다. 특히 유아는 일찍부터 물리.생물 현상의 규칙성이나 법 칙의 제약성을 인식할 뿐 아니라 이러한 현상에 대해 사회적 규범에 따르거나 자발적으로 행해진 사람의 행동에 대해서 와는 다른 판단을 한다(Browne \& Woolley, 2004; Kalish, 1998; Rosengren \& Hickling, 1994; Schult \& Wellman, 1997)고 알려져 있다. 이를 고려할 때, 유아가 타인이 전달한 물리.생물 현상 관련 정보를 듣고 평가하는 데 있어서도 직관이 강하게 적용
될 것이라 추측된다. 특히 물리.생물 현상에 대한 정보는 그동 안의 연구들(Chan \& Tardif, 2013; Mercier, Bernard, \& Clément, 2014)에서 주로 초점을 두어 왔던 대상의 명칭 정보나 상황특 정적인 에피소드 사건 정보와는 다르다. 물리.생물 영역의 정 보는 탐색과 검증을 거쳐 더 넓게 일반화되는 지식이 될 수 있 으므로(Gelman, 2000; Gopnik \& Schulz, 2007) 이를 활용하여 유아 정보 평가 연구를 수행하는 것은 이점을 가진다.

본 연구는 유아의 직관과 특정 현상의 가능성 판단 간의 관계를 살펴본 선행연구들의 영향을 받았다. Lane과 Harris (2015)의 연구에서 3-8세 아동은 정보가 물리.생물 영역의 직 관에 부합하는지의 여부에 따라 현상의 가능성을 다르게 평가 했고, 70 개월인 유아는 49개월인 유아에 비해 직관에 부합하 지 않는 현상의 가능성을 회의적으로 보는 경향을 더 뚜렷하 게 보였다. 더불어 49 개월 유아는 정보를 통해 소개된 대상의 존재 가능성에 대해서는 정보의 직관부합성에 따라 서로 다 른 평가를 하지 않은 반면, 정보를 통해 제시된 현상의 실현 가 능성에 대해서는 두 가지 정보 조건 간에 구분된 평가를 하였 다. 이 연구의 결과들은 타인이 말로 전달한 정보의 내용으로 서 물리.생물 현상이 유아의 직관에 부합하는지 여부에 따라 그것의 가능성 평가를 다르게 평가하는 양상이 4세경부터 초 보적으로 나타나며 그 이후 더 확고해짐을 보여주었다. 또한 사람이나 그 외의 대상이 보여주는 다양한 에피소드 사건들에 초점을 두고 실현 가능성.불가능성에 대한 유아의 인식을 살 펴본 연구들(Browne \& Woolley, 2004; Johnson \& Harris, 1994; Kalish, 1998; Rosengren \& Hickling, 1994; Schult \& Wellman, 1997; Shtulman, 2009; Shtulman \& Carey, 2007)에서 3-4세경 의 유아는 물리.생물 영역의 직관이나 기대를 강하게 위반하 는 사건을 일상적인 사건이나 의도에 의한 사건과 분명히 구 분하고(Kalish, 1998; Schult \& Wellman, 1997; Shtulman, 2009; Shtulman \& Carey, 2007), 마법이 아니라면 현실적으로 불가능 하다는 인식을 보여주었다(Browne \& Woolley, 2004; Johnson \& Harris, 1994; Rosengren \& Hickling, 1994). 이 결과들을 통해 서 꽤 어린 연령에서도 어떤 사건이나 현상이 가능한지를 판 단할 때 이미 가지고 있는 직관에 부합하는지 여부를 단서로 활용하며 특히 물리.생물 현상을 유발하는 요인들의 제약성을 강하게 인식함을 확인할 수 있다.

그러나 그동안의 유아 대상 연구들은 타인이 전달한 발화문 형태의 정보가 그럴듯한지를 평가하는 과정을 살펴보지는 않 았다. 유아가 독립된 화자인 정보제공자로부터 정보를 직접 전 달받을 때, 이 정보는 사회적 의사소통의 맥락을 가진다. 유아 가 친숙하고 믿을만한 정보제공자의 말도 지식 부족, 실수, 왜 
곡, 눈에 보이지 않는 의도나 또 다른 목적 등의 다양한 이유로 때때로 틀릴 수 있음을 인식하며 그 정보를 의심하고 비판적인 관점에서 살피는 것은 꽤 도전적인 일이다(Heyman, 2008; Jaswal \& Kondrad, 2016; Mills, 2013). 정보제공자가 직접 정보를 전하 는 상황에서 유아가 물리.생물 현상 정보의 타당성을 평가할 수 있을지, 그 양상은 어떠할지 살펴볼 필요가 있다. 정보의 타당성 을 직접 평가하는 데 있어서 나타나는 발달적 변화는 현상의 가 능성을 평가하는 데 있어서의 변화와 유사하게 확인될 수도 있 고 아니면 약간 늦을 수도 있을 것이다. 선행연구 고찰을 토대 로 단서를 활용한 정보 평가가 가능해지고 다른 사람의 말에 대 한 무조건적인 신뢰가 극복되기 시작하는 연령을 4세 정도라 보며, 물리.생물 직관에 부합하거나 부합하지 않는 정보에 대한 차별적인 평가가 본격적으로 나타나는 기점을 대략 4세에서 5 세 사이로 가정한다. 더불어 본 연구에서는 Lane과 Harris (2015) 의 연구에서 4 세부터 취학 전 연령에 이르는 약 2 년 사이에 나타 났던 연령차를 보다 면밀히 살펴볼 필요가 있다고 판단하고, 그 중에서도 이 시기에 지속적으로 이루어지는 발달적 변화가 무 엇에 토대를 둘지 그것을 밝히는 데에도 관심을 둔다.

다음으로, 유아의 정보 평가에 단서가 될 수 있는 다른 정보 특성은 정보의 주장성(assertiveness)이다(Bascandziev \& Harris, 2016; Sperber et al., 2010). 유아가 들은 정보에 대해 정확한 지 식을 가지고 있지 않다면, 정보의 진위 여부는 유아에게 확실 하지 않다. 이 경우에 타인의 정보는 주장적인(argumentative) 성격을 가진다(Mercier et al., 2014). 성인과 유아의 의사소통 맥락에서 서로 요구를 충족시키고 의미 전달을 충분히 하기 위해 정보와 설명이 연속적으로 이어지는 것은 자연스럽다. 문장 형식의 정보에 덧붙는 설명도 정보의 주장성 수준을 변 화시켜줄 수 있다.

일반적으로 설명은 어떤 일이나 대상에 대해 상대방이 잘 알고, 잘 이해할 수 있도록 돕기 위해 제공되는 것이다(Brewer,

Chinn, \& Samarapungavan, 1998; Keil, 2006; Lombrozo, 2006). 인과성에 대한 이해와 인과지식 획득이 인지발달에 기여하는 바가 크다는 점이 꾸준히 밝혀짐에 따라 그동안의 많은 연구 들은 설명에 대한 유아의 선호나 민감성 발달을 주로 인과적 설명을 중심으로 논의해왔다(Gopnik \& Schulz, 2007; Legare, 2012; Walker et al., 2017). 다만 이와 대조적으로 설명의 세부 적인 특성에 따라 유아가 이것을 이해하고 받아들이는 양상 이 어떻게 달라지는지와 또 다른 설명의 유형이 유아의 사고 에 어떠한 영향을 미치는지 등을 밝히려는 노력은 두드러지 지 않았다. 그러나 실제로 부모나 교사는 유아의 이해를 돕 기 위한 전략으로 설명의 다양한 유형을 활용한다(Gil \& Park,
2013; Pellegrini, Brody, \& Sigel, 1985; E. Y. Sung et al., 2011). 그 중 하나는 대상이나 현상의 표면적인 양상을 지각적으로 기술 하는 방식의 묘사를 활용하는 것이다(Brewer et al., 1998; Mills, Danovitch, Rowles, \& Campbell, 2017). 유아가 어머니와 그림 책을 읽는 상황에서 일어나는 언어적 상호작용에 대한 연구 들은 인과적인 이야기나누기 전략 뿐 아니라 모습이나 속성 에 대한 묘사를 활용하는 전략을 하나의 설명 전략으로 제시 하였고, 묘사적 설명은 일상 속에서 실제로 두루 활용된다(S. J. Choi \& Kwon, 2018; Haden, Reese, \& Fivush, 1996; Y. J. Han, 2000; Pellegrini et al., 1985). 이 때 인과적 설명과 묘사적 설명 은 목적과 필요에 의해 어떤 내용을 새로 담은 후 제공되는 것 이라는 점에서 반복을 활용한 설명과는 다르다. 일반적으로 유아는 이미 접한 내용을 반복하는 순환적(circular) 설명이 아 닌 새로운 정보를 주는 비순환적(non-circular) 설명에 분명한 선호를 보인다(Corriveau \& Kurkul, 2014; Mercier et al., 2014) 고 알려져 있다. 위의 결과들은 유아가 타인에 의해 제공되는 다양한 유형의 설명에 민감성을 가짐을 보여준다.

한편, 유아는 누군가의 주장이 근거를 가지는지 여부와 그 근거의 유형이 무엇인지에 따라 주장에 대한 평가를 달리한 다. 4-5세 유아는 모르는 대상의 명칭이나 외양적 특성에 대 해 보인 정보제공자의 정보 오류가 지각적인 접근성 부족으 로 인해 발생한 것일 때 후속 상황에서 그 정보제공자에게 신 뢰를 유지하며(Kondrad \& Jaswal, 2012; Nurmsoo \& Robinson, 2009), 물체의 현재 위치와 관련한 정보제공자의 주장이 소망, 가장, 추측 등이 아니라 교사의 증언, 지각적 확인, 추리 등에 토대를 둘 경우에 더 나은 정보라 여긴다(Koenig, 2012). 주장 의 근거에 대한 유아의 차별적인 인식을 보여주는 이 결과들 은 설명의 질에 대한 민감성을 확인시켜준 연구들과 함께 정 보에 대한 부연 설명의 존재와 그 유형이 유아의 정보 평가에 또 하나의 단서가 될 것이라는 가정을 지지해준다.

본 연구에서는 물리.생물 현상에 대한 정보가 있을 때 이에 대한 부연 설명의 효과에 초점을 둔 연구가 아직 없다는 점에 주목하였다. 발생 원리나 기제를 가질 수 있는 물리.생물 현상 의 정보와 그 정보를 직접 뒷받침하기 위해 제공되는 설명이 제공될 때에는 설명을 단독으로 살피는 것이 아니라 정보와 설 명의 내용 간 일관성(coherence)을 고려하여 살피는 것이 요구 된다. 이는 정보의 답으로 제공된 설명이 유용한 내용을 담고 있는지를 순환성(circularity)이라는 문장 형식에 기초하여 단순 히 비교하는 것이나 혹은 전달된 정보가 대상의 명칭이나 위치 와 같이 내용상 본질적인 근거를 가지지 않을 때 그 주장에 대 한 근거에 따라 구분된 반응을 보이는 것과는 다를 수 있다. 또 
한 유아는 일상 속에서나 교수 상황을 통해 새로운 정보와 다 양한 설명을 빈번하게 전달받는데 이 때 설명이 존재하는 이 유와 필요성, 그리고 그것이 가질 수 있는 내용이나 특성은 인 과성의 범위를 넘어선다. 그동안 유아가 보이는 설명의 유형 에 대한 민감성 연구들이 주로 인과적 설명(Frazier et al., 2009; Frazier, Gelman, \& Wellman, 2016; Kurkul \& Corriveau, 2018)에 초점을 두어 왔고 최근 순환적 설명과 비순환적 설명 간의 차 이(Baum, Danovitch, \& Keil, 2008; Corriveau \& Kurkul, 2014; Mercier et al., 2014)를 밝히는 연구들도 이루어졌지만 비순환 적 설명으로서 인과적 설명과 비인과적 설명 간에 나타나는 유 아의 반응 차이를 명확히 확인시켜주지 못했다는 아쉬움을 가 진다. 설명이 활용되는 맥락을 넓힘과 동시에 설명이 가질 수 있는 유형을 다양화하는 방법으로 설명의 역할과 효과에 대해 밝히는 연구들이 더 이루어져야 한다. 구체적으로 정보에 대한 인과적인 이해를 높이고자, 표면적 양상의 맥락적인 이해를 높 이고자, 그리고 의미를 반복하고자 인과적, 묘사적, 순환적 설 명이 각각 추가되는 경우에 정보의 그럴듯함에 대한 유아의 평 가가 어떻게 달라지는지를 살펴볼 필요가 있다. 이 때 길이가 짧지 않은 문장 형식의 설명의 질에 대한 민감성이 이전에 비 해 본격적으로 향상되는 시기가 4세경이라는 점(Corriveau \& Kurkul, 2014; Mercier et al., 2014)을 고려할 수 있다. 본 연구는 4세 이후의 유아가 물리.생물 현상의 정보를 인과적, 묘사적, 순환적 설명과 함께 총체적으로 살피는 과정에 어떻게 관여하 는지를 규명할 필요가 있다고 보며, 이것이 정보가 직관에 부 합하는지 여부와 설명의 유형에 따른 유아의 정보 평가에 대해 확장된 이해를 제공할 것이라 기대한다.

유아는 성장을 거치며 직관 뿐 아니라 다양한 사전지식과 경 험들을 축적해나간다. 유아가 직관을 넘어 인식적인 수준에서 의 탐색과 반영적 사고를 통해 정보를 살필 수 있다면 외부에서 들어오는 정보와 관련된 지식과 경험의 맥락이 더 광범위하게 활성화되어 더 체계적인 정보 평가를 가능해질 수 있다(Mercier $\&$ Sperber, 2009; Sperber \& Wilson, 1995). 본 연구에서는 유아기 내에서도 정보를 합리적으로 평가하는 능력에 있어 지속적인 향상이 있을 것이라 예상하며, 타인의 말에 대한 무분별한 신뢰 를 극복하기 시작하는 시기인 4세 이후 유아를 대상으로 정보 가 직관에 부합하는지 여부, 설명 유형 및 여부에 토대를 둔 정 보 평가가 어떻게 나타나는지, 그 과정이 연령에 따라 어떠한 변화를 보이는지를 살펴보고자 한다. 이를 통해 본 연구는 적응 적으로 의사소통을 나누는 존재로서 유아가 다른 사람이 제공 한 정보의 평가에 적극 관여함으로써 인지발달을 도모해나갈 잠재력을 가지는지를 증명하는 시도를 할 것이다. 또한 유아가
다각적인 관점에서 정보를 탐색하는 능력을 길러나갈 수 있도 록 돕기 위한 실천적 제안을 할 수 있을 것이다.

\section{연구문제 1}

유아의 정보 평가는 정보의 직관부합성, 연령에 따라 유의한 차이가 있는가?

\section{연구문제 2}

설명이 추가된 후, 유아의 정보 평가는 정보의 직관부합성, 설 명의 유형, 연령에 따라 유의한 차이가 있는가?

\section{연구문제 3}

설명 전후의 유아의 정보 평가에 유의한 차이가 있는가?

\section{Methods}

\section{연구대상}

본 연구에서는 서울과 경기도의 어린이집 총 8 곳에서 4 세 유 아 72 명, 5 세 유아 86 명, 총 158 명의 유아를 연구 대상으로 선 정하였다. 전체 유아의 평균연령은 60.78세였고, 연령별로 4 세 53.86개월, 5세 66.57개월이었다. 사전검사로 Pae, Lim, Lee 와 Chang (2004)의 구문의미 이해력 검사를 실시한 결과, 4 세 와 5 세의 $90 \%$ 이상이 연령표준점수 이상의 점수를, 그 외의 유아들도 연령별 평균에 매우 근접한 점수를 얻었다. 모든 유 아가 문장 수준의 구두정보 평가 과제 참여에 문제가 없음을 확인하였다. 연구대상 유아의 특성은 Table 1 에 제시하였다.

Table 1

Age and Gender of the Participants

\begin{tabular}{lccccc}
\hline & \multicolumn{2}{c}{ Age in month } & \multicolumn{2}{c}{ Gender $(n)$} & \\
\cline { 2 - 5 } Age & $M$ & Range & Boys & Girls & Total \\
\hline 4 & 53.86 & $48-59$ & 42 & 30 & 72 \\
5 & 66.57 & $60-71$ & 44 & 42 & 86 \\
\hline Total & 60.78 & $48-71$ & 86 & 72 & 158 \\
\hline
\end{tabular}

\section{연구도구}

$$
\text { 정보와 설명의 구성 및 음성화 }
$$

대표 직관의 선정과 사례 구성 유아 정보 평가 과제는 물리.생 
Table 2

Items of Physical and Biological Intuitions Selected in the Study

\begin{tabular}{|c|c|c|c|}
\hline \multicolumn{3}{|c|}{ Physical intuition } & Biological intuition \\
\hline Physics1 & Continuous motion of an object due to inertia & Biology 1 & Direction of quantitative growth of an animal \\
\hline Physics2 & Falling motion of an object due to gravity & Biology2 & Stages of breeding and growth of an animal \\
\hline Physics3 & Permanence and inactivity of an object & Biology3 & Nutrient intake and physical growth of an animal \\
\hline Physics 4 & Rigidity and spatial continuity of an object & & Nutrient intake and energy generation of an animal \\
\hline Physics 5 & $\begin{array}{l}\text { Non-reversible change in the shape of an object due } \\
\text { to physical force }\end{array}$ & Biology 5 & $\begin{array}{l}\text { Physical condition and motor function of an animal with } \\
\text { no wings }\end{array}$ \\
\hline Physics6 & $\begin{array}{l}\text { Change in location/existence of an object due to a } \\
\text { physical action (e.g., throwing away) }\end{array}$ & Biology 6 & $\begin{array}{l}\text { Function of a specific body part(e.g., eyes, mouth) of an } \\
\text { animal }\end{array}$ \\
\hline
\end{tabular}

물 현상에 대한 정보에 설명이 추가되기 전과 후 유아의 정보 평가를 각각 측정하기 위한 목적으로 사용하였다. 음성자료는 정보제공자의 음성으로 제공되는 정보와 설명을 말하며, 물리. 생물 현상 관련 직관부합 정보 및 직관비부합 정보, 그리고 각 정보에 대한 부연인 인과적 설명, 묘사적 설명, 순환적 설명을 포함한다. 정보의 구성은 선행연구들에 기초하여 물리 영역과 생물 영역의 대표 직관을 선정한 후 직관이 적용되거나 적용되 지 않는 각각의 사례를 만드는 단계, 이를 구체화하여 정보 문 항으로 활용할 직관부합 정보와 직관비부합 정보의 쌍을 구성 하는 단계로 진행되었다. 첫 단계에서 유아의 초보적인 지식으 로서의 물리 영역(Baillargeon, 1986, 1994; Spelke, 1994; Spelke et al., 1992) 및 생물 영역(Carey, 1985; Gelman, 2000; Gelman et al., 1983; Inagaki \& Hatano, 1996, 2006; Jones et al., 1991; Keil, 1995; Rosengren et al., 1991)의 초보지식과 신념 형성과 발달을 규명한 연구들을 통해 주요 직관을 일차적으로 선정하고 틀을 세웠다. 그리고 정보제공자가 전달하는 물리.생물 현상의 가 능성에 대한 4-8세 아동의 평가를 살펴본 연구(Lane \& Harris, 2015)와 물리.생물 영역의 기대위반적인 사건에 대한 3-5세 유 아의 가능성 판단에 초점을 둔 연구들(Browne \& Woolley, 2004; Johnson \& Harris, 1994; Kalish, 1998; Schult \& Wellman, 1997; Shtulman \& Carey, 2007)에서 사용된 과제 문항을 통해 구성의 틀을 보완하였다. 본 연구에서 정보 문항의 기초로 활용될 직 관으로 총 12 개가 선정되었으며, 이는 아래 Table 2에 제시하 였다. 구체적으로, 관성에 따른 물체의 움직임, 중력에 따른 물 체 움직임, 물체의 영속성 및 비활동성, 물체의 견고성과 공간 적 연속성, 물리적 힘에 따른 물체의 비가역적인 형태변화, 물 리적 행위에 따른 물체의 위치/존재 변화가 물리 영역의 직관 으로, 동물의 양적 성장의 방향성, 동물의 번식과 성장 단계, 동 물의 섭취와 신체적 성장, 동물의 섭취와 활력 생성, 동물의 신 체적 조건과 운동성, 동물의 특정 신체 부위와 기능이 생물 영
역의 직관으로 선정되었다. 그 다음, 이를 토대로 직관을 따르 는 사례와 직관에 반하는 사례의 쌍을 12 개 만들었다. 예를 들 어, 관성과 물체의 움직임에 대한 물리 1 번에서 직관을 따르는 사례는 외부로부터 방해가 없을 때(이전상황) '현재 물체의 운 동 상태가 유지되는 것(후속상황)'이며, 직관에 반하는 사례는 동일한 이전상황에서 '갑작스럽게 운동이 정지되는 것(후속상 황)'이다. 또한 동물의 섭취와 성장에 대한 생물3번에서 직관을 따르는 사례는 동물이 영양분을 꾸준히 섭취할 때(이전상황) '신장이 증가하는 것(후속상황)'이며, 직관에 반하는 사례는 동 일한 이전상황에서 '신장이 줄어드는 것(후속상황)'이다.

정보 및 설명 문장의 구성 직관을 따르거나 반하는 사례를 물 체와 동물을 주어로 하고 일상적으로 말하는 방식으로 구체화 하여 정보 문항을 구성하였다. 직관부합 정보와 직관비부합 정보는 시간의 순서에 따른 두 가지 상황으로 표현되는 물리. 생물 현상의 내용을 포함한다. 이 때 후속상황만 서로 다르며, 직관부합 정보는 직관에 부합하는 현상이, 직관비부합 정보에 는 직관에 부합하지 않는 현상이 문장 형식으로 담긴 것이다. 물리 영역 정보에서는 직관이 원활하게 적용되도록 돕기 위해 주어가 되는 물체에 특정 모양이나 돌, 쇠, 종이 등과 같은 소 재의 특성을 하나씩 부여하였다. 예를 들어, 물리 1 번 문항에서 “공을 닮은 이 물건은 내리막길에서 구르기 시작하면 길 아래 로 계속 굴러가.”는 직관부합 정보, “공을 닮은 이 물건은 내리 막길에서 구르기 시작하면 가다가 중간에 갑자기 멈춰.”는 직 관비부합 정보이다. 그리고 생물3번 문항에서 “이 아기동물은 매일 먹이를 잘 먹으면 키가 점점 자라.”는 직관부합 정보, “이 아기동물은 매일 먹이를 잘 먹으면 키가 점점 줄어."는 직관비 부합 정보이다. 최종적으로 작성된 정보문은 12 개의 직관별 로 2 개씩, 총 24 개였다.

한편 한 쌍으로 구성된 직관부합 정보와 직관비부합 정보 
Table 3

Examples of Information and Explanation Statements Used in the Study

\begin{tabular}{|c|c|c|c|c|}
\hline & $\begin{array}{l}\text { Intuitiveness } \\
\text { of information }\end{array}$ & Information statements & $\begin{array}{c}\text { Types of } \\
\text { explanation }\end{array}$ & Explanation statements \\
\hline \multirow[t]{6}{*}{ Physics1 } & \multirow[t]{3}{*}{ Intuitive } & \multirow{3}{*}{$\begin{array}{l}\text { This object, which looks like a ball, will } \\
\text { continue rolling down if it starts rolling } \\
\text { on a downhill path. }\end{array}$} & Casual & $\begin{array}{l}\text { This is because the ball can continue rolling when } \\
\text { there is nothing blocking the downhill path. }\end{array}$ \\
\hline & & & Descriptive & $\begin{array}{l}\text { It rolls and rolls like a round wheel until the end } \\
\text { of the downhill. }\end{array}$ \\
\hline & & & Circular & $\begin{array}{l}\text { It does not stop once it starts rolling down the } \\
\text { hill. }\end{array}$ \\
\hline & \multirow[t]{3}{*}{ Counterintuitive } & \multirow{3}{*}{$\begin{array}{l}\text { This object, which looks like a ball, will } \\
\text { suddenly stop midway if it starts rolling } \\
\text { downhill. }\end{array}$} & Casual & $\begin{array}{l}\text { This is because the ball has the power to stop } \\
\text { itself when it starts moving faster. }\end{array}$ \\
\hline & & & Descriptive & $\begin{array}{l}\text { It stops midway down the hill as if someone } \\
\text { grabbed it and stopped it. }\end{array}$ \\
\hline & & & Circular & $\begin{array}{l}\text { It stops midway once it starts rolling down the } \\
\text { hill. }\end{array}$ \\
\hline \multirow{5}{*}{ Biology3 } & \multirow{2}{*}{ Intuitive } & \multirow{2}{*}{$\begin{array}{l}\text { This baby animal grows taller if it eats } \\
\text { well everyday. }\end{array}$} & Descriptive & The head rises high like a tall tree standing high. \\
\hline & & & Circular & $\begin{array}{l}\text { Its body length gets longer when the animal eats } \\
\text { enough each day. }\end{array}$ \\
\hline & \multirow[t]{3}{*}{ Counterintuitive } & \multirow[t]{3}{*}{$\begin{array}{l}\text { This baby animal gets shorter if it eats } \\
\text { well everyday. }\end{array}$} & Casual & $\begin{array}{l}\text { It is because animal food contains things that can } \\
\text { make the body shrink. }\end{array}$ \\
\hline & & & Descriptive & $\begin{array}{l}\text { The head drops down to the ground like a melted } \\
\text { snowman. }\end{array}$ \\
\hline & & & Circular & $\begin{array}{l}\text { Its body length gets shorter when the animal eats } \\
\text { enough each day. }\end{array}$ \\
\hline
\end{tabular}

에 각각 세 가지 유형의 설명을 부연하였다. 인과적 설명은 인 과 요인이나 발생 원리 등을 명시하는 형태를, 묘사적 설명은 유아에게 친숙한 대상이나 모습에 기초한 비유를 활용하여 현 재 양상을 지각적으로 구체화하는 형태를, 순환적 설명은 새 롭게 추가되는 내용이 없이 유사어를 사용하여 정보의 의미를 반복하는 형태를 가진다. 예를 들어, 물리 1 번 문항의 직관부 합 정보에 더해지는 설명에서 "기울어진 길에서 앞을 막는 게 없을 때 계속 움직일 수 있어서 그래."는 인과적 설명, “동그란 바퀴가 구를 때처럼 길 끝까지 데굴데굴 굴러 내려가.”는 묘사 적 설명, "내려가는 길에서 구르기 시작하더니 길 아래로 멈추 지 않고 굴러가.”는 순환적 설명이다. 그리고 생물3번 문항의 직관비부합 정보에 더해지는 설명에서 “먹는 먹이에 몸의 크 기를 줄어들게 하는 것이 들어 있어서 그래."는 인과적 설명, "녹아서 키가 슬며시 작아진 눈사람처럼 땅 가까이 쑤욱 내려 와."는 묘사적 설명, “날마다 먹이를 충분히 먹을수록 몸의 길 이가 조금씩 더 줄어."는 순환적 설명이다. 준비된 설명 문장
은 총 72 개였다. 단, 유아가 하나의 문항에 대해 직관부합 정 보와 직관비부합 정보를 각각 받을 때, 설명의 유형에 따른 효 과 학습이나 방해를 피하기 위해 문항 내에서 개인이 받는 설 명의 유형을 한 개로 제한하였다. 정보와 설명은 해당 연령의 평균적인 어휘력과 구문이해력 수준을 고려하여 구성되었다. 그리고 정보 및 설명 각 문장의 글자 수를 계산 한 후에 동일 문항 내의 정보 간, 동일 정보 내의 설명 간에 글자 수가 최대 한 유사하도록 내용을 일부 수정하였다. 정보와 설명 문장 구 성의 전 단계에서 아동학 석사 및 박사 학위 이상의 학력을 소 지하고 보육 경험이 있는 8 인과 적합성과 타당성을 반복적으 로 점검하였다. 또한 세 차례의 예비조사를 통해 수정.보완하 였다. 최종적으로 사용한 정보 및 설명의 예시는 Table 3에 제 시하였다.

정보와 설명의 음성화 정보와 설명은 정보 평가 과제에서 음 성자료로 활용할 수 있도록 표준어를 사용하며 어감이 자연스 
러운 성인여성의 목소리로 녹음하였다. 미리 모집하여 사전훈 련을 거친 성인여성 20 명 중 안정적인 음성을 제공한 12 명을 추리고 반복 녹음한 음성 중 가장 적절한 음성을 선별하는 과 정을 거쳤다. 각 정보제공자는 하나의 문항에 해당하는 음성 (정보 2개, 설명 6개)을 제공하였으며, 이는 문항 내 음성 특성 에 따른 차이가 반영되지 않도록 한 것이다. 수집된 문장의 발 화 길이는 정보 문장 24 개 평균 6-8초 사이, 설명 문장 72 개 평 균 6-7초 사이였다. 준비된 wav파일은 그림자료들과 함께 프 레젠테이션 프로그램 과제제시화면에 삽입하였다.

\section{보조자료 그림과 제시화면의 구성}

그림자료는 구두 정보에서 언급하는 현상에 대한 유아의 표 상과 언어적 이해를 돕기 위해 활용되는 것으로, 주어가 되는 물체나 동물의 형태를 표현한 대상그림과 정보에 담긴 현상 을 시간의 순서에 따라 이전상황과 후속상황으로 각각 시각화 한 상황그림의 쌍을 포함한다. 대상그림에서 각 물체의 형태 는 친숙한 기본입체도형을 맞붙여 결합하고 선이나 무늬를 추
가하는 방식으로, 동물의 외양은 척추동물 분류별 대표 동물 들과 유사하되 직관과 무관한 부분을 일부 변형하는 방식으로 구성하였다. 그리고 인지처리의 혼란을 방지하기 위해 대상그 림과 상황그림을 두 가지 유형 세트로 준비하고, 직관부합 정 보와 직관비부합 정보 쌍에 대해 물체나 동물을 서로 다른 형 태로, 교차 제공하는 것으로 하였다. 대상그림 및 상황그림(총 72종) 제작은 시안 구상, 밑그림과 채색 작업 단계를 거쳤다. 물체에는 돌, 쇠, 유리 등의 소재감을 주고 동물에는 털과 비늘 등 외양의 현실성을 부여하였다. 그림자료 제작에 미술 및 산 업디자인 전문가 2 인의 도움을 받았으며, 정보 및 설명 구성에 서와 같이 적합성과 타당성을 점검하였다.

본 과제 수행에는 프레젠테이션 소프트웨어인 Microsoft PowerPoint 2016 프로그램과 노트북을 활용하였고, 소프트웨 어 기반 제시화면에는 각 문항별 진행 순서에 따라 정보 및 설명 음성, 보조자료 그림들을 통제된 방법으로 삽입하였다. Table 4를 통해 확인할 수 있듯이, 대상그림은 첫 단계인 '대상 의 소개’ 시에, 이전상황과 후속상황을 포함하는 상황그림 세 트는 '정보 음성 제공-정보 평가 질의응답-설명 음성 제공-설명

Table 4

An Example of the Presentation Screen and Supplementary Drawings

\begin{tabular}{|c|c|c|c|c|}
\hline & \multicolumn{2}{|c|}{ Physics2 } & \multicolumn{2}{|c|}{ Biology 1} \\
\hline Sequence & Intuitive & Counterintuitive & Intuitive & Counterintuitive \\
\hline
\end{tabular}

1. An introduction

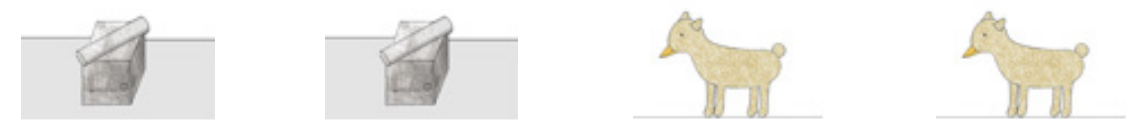

2. The presentation of an information

3. [Q\&A] Pre-explanation evaluation of information

4. The presentation of an explanation

5. [Q\&A] Post-explanation evaluation of information

Table 5

Categories and Questions of Evaluation of Information

\begin{tabular}{lll}
\hline \multicolumn{1}{c}{ Variables } & \multicolumn{1}{c}{ Questions } & \multicolumn{1}{c}{ Scores } \\
\hline $\begin{array}{l}\text { Pre-explanation } \\
\text { evaluation }\end{array}$ & $\begin{array}{l}\text { Is this person's story you about that object/animal, which } \\
\text { you just heard, plausible or implausible? }\end{array}$ & $\begin{array}{l}\text { 1: Plausible, 0: Implausible } \\
\text { Total (Intuitive/Counterintuitive information } \\
\text { condition respectively): } 0-12\end{array}$ \\
$\begin{array}{l}\text { Post-explanation } \\
\text { evaluation }\end{array}$ & $\begin{array}{l}\text { Is this person's story you about that object/animal, which } \\
\text { you heard earlier, plausible or implausible? What do you } \\
\text { think about it now? }\end{array}$ & $\begin{array}{l}\text { 1: Plausible, 0: Implausible } \\
\text { Total (Intuitive/Counterintuitive information } \\
\text { condition respectively): } 0-12\end{array}$ \\
\hline
\end{tabular}


후 정보 평가 질의응답'으로 이어지는 단계에 노트북 전체 화 면을 통해 유아에게 제시하였다. 유아는 조사자의 진행에 따라 각 문항별 정보와 설명을 음성파일을 통해 제공받고, 정보에 대한 표상과 이해를 돕는 보조자료인 그림자료들을 화면을 통 해 제시받으며, 정보 평가에 대한 질의응답에 참여하였다.

\section{유아 정보 평가 과제}

유아의 정보 평가는 설명 전과 후 총 2 회에 걸쳐 측정하였다. 두 번의 평가는 정보의 타당성 여부, 즉 정보가 타당한지 아닌 지에 대한 유아의 평가를 맞다 혹은 틀리다 라는 두 개의 선택 지 중에 하나를 고르도록 하는 선택형 판정의 방식으로 측정 하였다. 측정 점수화 기준은 Table 5에 제시하였으며, 맞다 라 고 응답한 경우 1점으로, 틀리다 라고 응답하거나 기타 응답 을 할 경우 0점으로 점수화하였다. 설명 전 정보 평가 점수와 설명 후 정보 평가 점수는 각각 응답의 합산으로 이루어져 정 보의 직관부합성에 따른 조건별로 0-12점의 점수범위를 가진 다. 이 때 정보 타당성 여부에 대한 평가를 확인하는 질문 시에 는 유아의 수행을 돕기 위해 양쪽 입 꼬리가 쳐진 모양으로 표 현된 찡그린 얼굴(틀리다)과 양쪽 입 꼬리를 올린 모양으로 표 현된 웃는 얼굴(맞다)의 두 가지 얼굴 표정 그림 카드를 활용 하였다. 본 연구에서 타당성은 유아에게 주관적으로 인식되는 타당성(plausibility)이며, 보편적 진리와 이치에 기준을 둔 타당 성(validity)이 아니다. 과제 수행 시, 정답을 맞히는 것이 아니 라 정보의 그럴듯함에 대한 유아의 생각을 묻는 것임을 설명 한 후 측정하였다. 유아 정보 평가 과제는 직관부합 정보 문항 12 개(물리 6개, 생물 6개)와 직관비부합 정보 문항 12개(물리 6 개, 생물 6개)를 제공받는 것으로 하고, 직관부합성에 따른 정 보 제공(2개의 순서 쌍), 적용대상의 유형(2개의 순서 쌍), 설명 의 유형(3개의 순서 쌍)에 따라 순서효과를 고려하여 무선화한 후, 이를 반영한 12 개의 본 과제 수행도구를 구성하였다. 이를 다시 연령별로 유아에게 무선 할당하였고, 과제 전반과 후반에 서 물리 영역 및 생물 영역의 문항의 제공 순서를 교차하였다.

\section{연구절차}

IRB의 연구승인을 받아 서울 및 경기도 소재 국공립 어린이집 과 직장어린이집 총 8 곳에서 유아 총 158 명을 대상으로 조사를 진행하였으며, 본 조사에 앞서 서울의 직장어린이집 두 곳에서 30 명의 유아를 대상으로 예비조사를 진행하였다. 정보의 직관 부합성 조건별 내용 상충으로 인한 인지적 혼동을 줄이기 위 해 본 과제를 2 회 차로 나누어 진행하였고, 모든 문항에서 직관
부합 정보와 직관비부합 정보가 회차 별로 각각 배치되게 하였 다. 1 회차 조사에서 사전검사와 본 과제 전반부(약 25 분 소요) 를, 2 회차 조사에서 본 과제 후반부(약 15 분 소요)를 진행하였 으며, 사이에 평균 1 일의 간격을 두었다. 조사의 수행은 사전훈 련을 받은 4 명이 담당하였고, 어린이집 내 조용한 공간에서 조 사자 1 인과 유아 간 일대일 면접으로 진행하였다.

\section{자료분석}

수집된 자료는 SPSS Win 25.0 (IBM Co., Armonk, NY) 프로그 램을 이용해 분석하였다. 유아의 일반적 특성과 사전검사 점 수를 알아보기 위해 빈도와 평균, 표준편차를 살펴보았다. 정 보의 직관부합성과 연령에 따른 설명 전 유아의 정보 평가 차 이를 알아보기 위해 반복측정 이원변량분석을, 정보의 직관 부합성, 설명의 유형, 연령에 따른 설명 후 유아의 정보 평가 차이를 알아보기 위해 반복측정 삼원변량분석을 시행하였 다. 그리고 두 번의 반복측정 변량분석에서 각각 상호작용효 과가 확인된 경우, 단순주효과 규명을 위해 독립표본 $t$-검정, Bonferroni 다중비교를 실시하였다. 마지막으로 설명 전후 정 보 평가를 비교하기 위해 대응표본 $t$-검정을 실시하였다.

\section{Results}

\section{설명 전 유아의 정보 평가}

정보의 직관부합성과 유아의 연령에 따른 유아의 정보 평가의 양상은 Table 6과 같다. 정보의 직관부합성과 연령에 따라 설 명 전 유아의 정보 평가에 차이가 있는지 확인하기 위해 반복 측정 변량분석을 실시한 결과는 Table 7과 같다. 그 결과, 연령 $(F=9.09, d f=1,156, p<.01)$ 과 정보의 직관부합성 $(F=396.81$, $d f=1,156, p$ <.001) 각각에 따른 주효과와 정보의 직관부합 성과 연령 간의 상호작용 효과 $(F=17.13, d f=1,156, p<.001)$ 가 유의했다. 먼저, 직관부합성의 주효과 $(F=396.81, d f=1,1$, $156, p<.001)$ 가 강하게 나타났다. 유아는 정보가 맞다는 응답 을 직관비부합 정보 조건에 비해 직관부합 정보 조건에서 유 의하게 더 많이 하였다. 이는 유아가 직관에 부합하지 않는 정 보에 비해 직관에 부합하는 정보를 더 타당하다고 평가한다는 결과이며, 이러한 양상은 두 연령에서 다르지 않게 나타났다.

또한 정보의 직관부합성과 연령 간의 상호작용 효과가 확 인되어 단순주효과 분석으로 독립표본 $t$-검정을 실시하였다. 
Table 6

Means and Standard Deviations of Variables (Pre-Explanation Evaluation of Information)

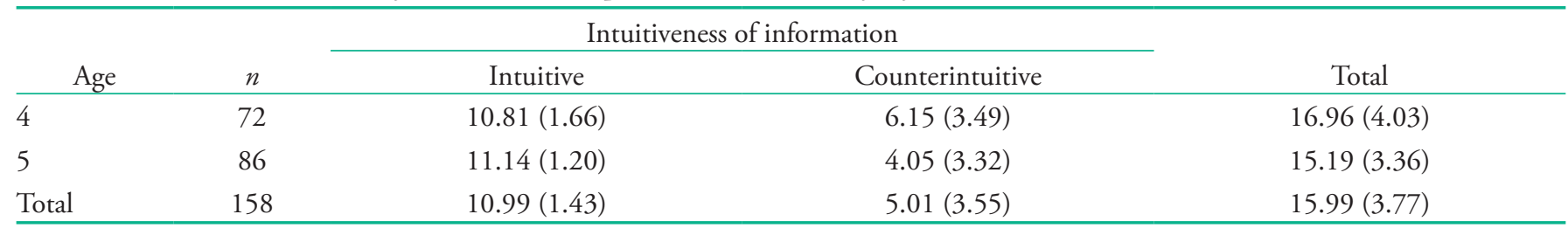

Table 7

Results of Repeated Measures ANOVA (Pre-Explanation Evaluation of Information)

\begin{tabular}{|c|c|c|c|c|}
\hline Source & SS & $d f$ & $M S$ & $F$ \\
\hline \multicolumn{5}{|l|}{ Between factor } \\
\hline Age & 61.55 & 1 & 61.55 & $9.09^{* *}$ \\
\hline \multicolumn{5}{|l|}{ Within factor } \\
\hline Intuitiveness of information & 2703.39 & 1 & 2703.39 & $396.81^{* * *}$ \\
\hline Error & 1062.79 & 156 & & \\
\hline
\end{tabular}

${ }^{* *} p<.01 .{ }^{* * *} p<.001$.

Table 8

Age-Related Differences in Pre-Explanation Evaluation of Information

\begin{tabular}{|c|c|c|c|c|c|}
\hline Intuitiveness of information & Age & $n$ & $M$ & $S D$ & $t$ \\
\hline \multirow[t]{2}{*}{ Intuitive } & 4 & 72 & 10.81 & 1.66 & -1.43 \\
\hline & 5 & 86 & 11.14 & 1.20 & \\
\hline \multirow[t]{2}{*}{ Counterintuitive } & 4 & 72 & 6.15 & 3.49 & $3.88^{* * *}$ \\
\hline & 5 & 86 & 4.05 & 3.32 & \\
\hline
\end{tabular}

${ }^{* * *} p<.001$.

Table 8에 제시한 바와 같이, 설명 전 유아의 정보 평가는 직관 부합 정보 조건에서 4 세 10.81 점 $(S D=1.66)$, 5세 11.14점 $(S D=$ $1.20)$ 으로 연령 간 유의한 차이가 없었으나 직관비부합 정보 조건에서 4세 6.15점 $(S D=3.49)$, 5세 4.05점 $(S D=3.32)$ 으로 4 세의 점수가 5 세의 점수보다 유의하게 높았다. Figure 1에서도 확인할 수 있듯이 전달된 정보가 직관에 부합할 때는 4 세 유아 와 5세 유아가 유사한 정도로 정보를 타당하다고 평가하였지 만, 정보가 직관에 부합하지 않을 경우에는 정보를 타당하다 고 평가하는 경향성은 5세 유아보다 4세 유아가 더 높게 보였 다. 정보를 타당하다고 평가하는 경향은 직관에 부합하지 않 는 정보를 전달받는 경우에서만 두 연령 간에 차이를 보인다 는 점과 구체적으로 4 세 유아는 5 세 유아보다 직관에 부합하 지 않는 정보를 더 타당하다고 평가한다는 점을 알 수 있었다.

\section{설명 후 유아의 정보 평가}

설명이 추가되었을 때, 정보의 직관부합성과 설명의 유형에 따른 설명 후 유아의 정보 평가의 양상은 Table 9와 같다. 정보 의 직관부합성과 연령에 따라 설명 후 유아의 정보 평가에 차 이가 있는지 알아보고자 반복측정 변량분석을 실시한 결과는 Table 10과 같다. 정보의 직관부합성 $(F=201.83, d f=1,156, p$ <.001)과 설명의 유형 $(F=3.39, d f=2,312, p<.05)$ 에 따른 주 효과가 유의했고, 연령의 주효과는 유의하지 않았다. 또한 정 보의 직관부합성과 연령 간의 상호작용 효과 $(F=17.76, d f=1$, $156, p<.001)$ 와 정보의 직관부합성과 설명의 유형 간의 상호 작용 효과 $(F=5.69, d f=2,312, p<.01)$ 가 유의했고, 설명의 유 형과 연령 간의, 정보의 직관부합성과 설명의 유형 및 연령 간 
Table 9

Means and Standard Deviations of Variables (Post-Explanation Evaluation of Information)

\begin{tabular}{|c|c|c|c|c|c|c|}
\hline \multirow[b]{2}{*}{ Intuitiveness of information } & \multirow[b]{2}{*}{ Age } & \multirow[b]{2}{*}{$n$} & \multicolumn{3}{|c|}{ Types of explanation } & \multirow[b]{2}{*}{ Total } \\
\hline & & & Causal & Descriptive & Circular & \\
\hline \multirow[t]{2}{*}{ Intuitive } & 4 & 72 & $3.42(0.96)$ & $3.21(0.99)$ & $3.32(0.84)$ & $9.94(2.43)$ \\
\hline & Total & 158 & $3.41(0.88)$ & $3.41(0.85)$ & $3.51(0.76)$ & $10.33(2.04)$ \\
\hline Counterintuitive & 4 & 72 & $2.57(1.21)$ & $2.31(1.36)$ & $2.18(1.39)$ & $7.06(3.34)$ \\
\hline
\end{tabular}

Table 10

Results of Repeated Measures ANOVA (Post-Explanation Evaluation of Information)

\begin{tabular}{|c|c|c|c|c|}
\hline Source & SS & $d f$ & $M S$ & $F$ \\
\hline \multicolumn{5}{|l|}{ Between factor } \\
\hline Age & 6.84 & 1 & 6.84 & 2.16 \\
\hline Error & 494.66 & 156 & 3.17 & \\
\hline \multicolumn{5}{|l|}{ Within factor } \\
\hline Intuitiveness of information & 440.74 & 1 & 440.74 & $201.83^{* * *}$ \\
\hline Intuitiveness of information $\times$ Age & 38.78 & 1 & 38.78 & $17.76^{* * *}$ \\
\hline Error & 340.66 & 156 & 2.18 & \\
\hline Types of explanation & 4.02 & 2 & 2.01 & $3.39^{*}$ \\
\hline Types of explanation $\times$ Age & 2.82 & 2 & 1.41 & 2.37 \\
\hline Error & 185.23 & 312 & .59 & \\
\hline $\begin{array}{l}\text { Intuitiveness of information } \\
\times \text { Types of explanation }\end{array}$ & 6.02 & 2 & 3.01 & $5.69^{* *}$ \\
\hline $\begin{array}{l}\text { Intuitiveness of information } \\
\times \text { Types of explanation } \times \text { Age }\end{array}$ & 1.97 & 2 & .98 & 1.86 \\
\hline Error & 165.24 & 312 & .53 & \\
\hline
\end{tabular}

${ }^{*} p<.05 .{ }^{* *} p<.01 .{ }^{* * *} p<.001$.

Table 11

Age-Related Differences in Post-Explanation Evaluation of Information

\begin{tabular}{|c|c|c|c|c|c|}
\hline Intuitiveness of information & Age & $n$ & $M$ & $S D$ & $t$ \\
\hline \multirow[t]{2}{*}{ Intuitive } & 4 & 72 & 9.94 & 2.43 & -1.72 \\
\hline & 5 & 86 & 10.65 & 1.59 & \\
\hline \multirow[t]{2}{*}{ Counterintuitive } & 4 & 72 & 7.06 & 3.34 & $3.13^{* *}$ \\
\hline & 5 & 86 & 5.33 & 3.53 & \\
\hline
\end{tabular}

${ }^{* *} p<.01$.

의 상호작용 효과는 각각 유의하지 않았다.

설명이 추가되기 전과 유사하게, 정보의 직관부합성 $(F=$ $201.83, d f=1,156, p<.001)$ 의 효과와 정보의 직관부합성과 연령 간의 상호작용 효과 $(F=201.83, d f=1,156, p<.001)$ 가 각각 유의하여 후자의 단순주효과를 분석하기 위해 독립표본 t-검정을 실시하였다. Table 11과 Figure 2를 통해 확인하면, 설 명 후 유아의 정보 평가는 직관부합 정보 조건에서 4세 9.94점 $(S D=2.43), 5$ 세 10.65 점 $(S D=1.59)$ 으로 두 연령 간 유의한 차 이가 없었으나 직관비부합 정보 조건에서는 4세 7.06점 $(S D=$ $3.34), 5$ 세 5.33 점 $(S D=3.53)$ 으로 4 세 유아의 정보 평가 점수가 
Table 12

Differences in Post-Explanation Evaluation of Information Depending on the Type of Explanation

\begin{tabular}{|c|c|c|c|c|c|c|}
\hline Intuitiveness of information & Types of explanation & $n$ & $M$ & $S D$ & $F$ & Bonferroni \\
\hline \multirow[t]{2}{*}{ Intuitive } & Causal & 158 & 3.41 & 0.88 & 1.87 & \\
\hline & Descriptive & 158 & 3.41 & 0.85 & & \\
\hline \multirow[t]{2}{*}{ Counterintuitive } & Causal & 158 & 2.23 & 1.32 & $8.26^{* *}$ & a \\
\hline & Descriptive & 158 & 1.94 & 1.43 & & $\mathrm{~b}$ \\
\hline
\end{tabular}

${ }^{* *} p<.01$.

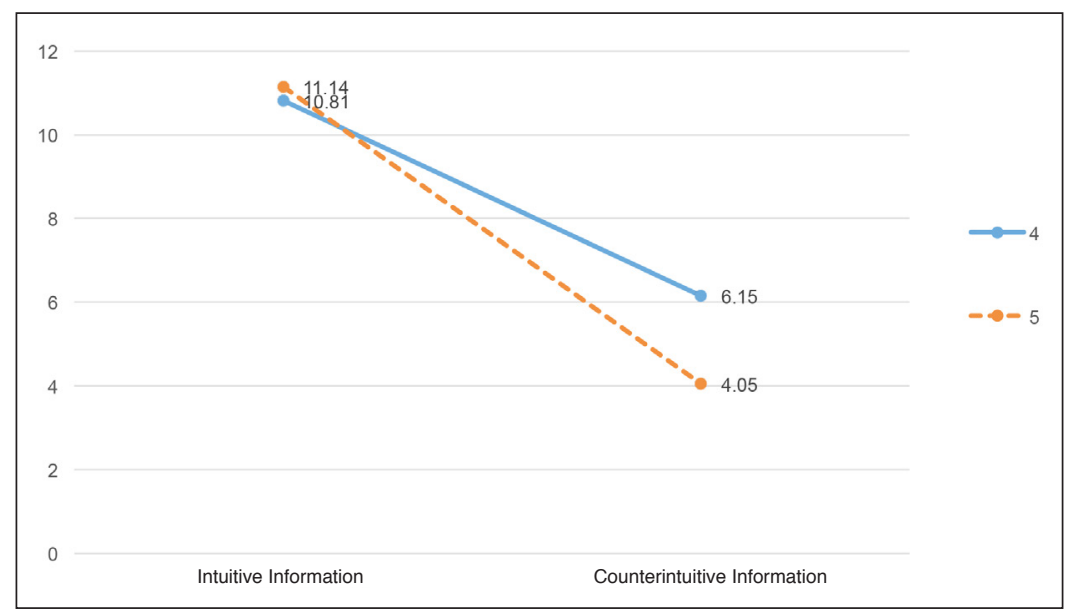

Figure 1. Differences in pre-explanation evaluation of information.

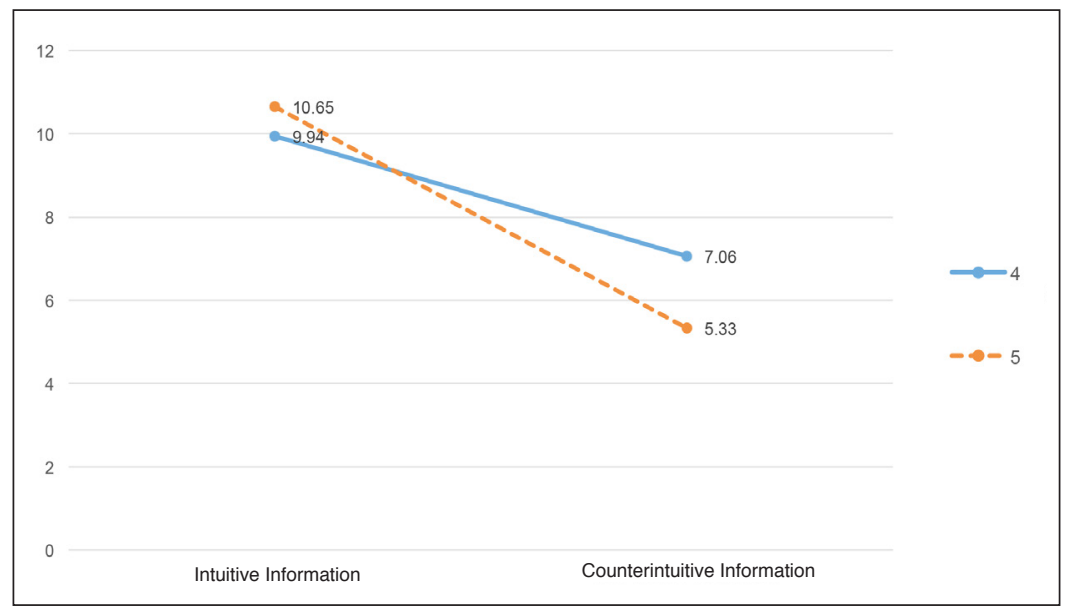

Figure 2. Differences in post-explanation evaluation of information.

5세 유아의 점수에 비해 유의하게 높았다. 정보에 설명이 추가 될 때, 정보만 제공된 경우에서와 유사하게 유아는 직관에 부 합하지 않는 정보를 직관에 부합하는 정보에 비해 덜 타당하 다고 평가하였으나 직관에 부합하지 않는 정보를 타당하다고
평가하는 경향은 4 세보다 5세에서 더 강했다. 이는 연령의 증 가에 따라 타인이 제공한 정보가 직관에 부합하지 않을 때 그 것이 사실일 가능성을 더 적게 인정한다는 점을 보여준다.

한편 정보의 직관부합성과 설명의 유형 간의 상호작용 효 
Table 13

Differences Between Pre-and Post-Explanation Evaluation of Information

\begin{tabular}{|c|c|c|c|c|c|c|c|}
\hline \multirow[b]{2}{*}{ Age } & \multirow{2}{*}{$\begin{array}{c}\text { Intuitiveness of } \\
\text { information }\end{array}$} & \multicolumn{2}{|c|}{ Explanation } & \multirow[b]{2}{*}{$n$} & \multirow[b]{2}{*}{$M$} & \multirow[b]{2}{*}{$S D$} & \multirow[b]{2}{*}{$t$} \\
\hline & & Type & Pre- / Post- & & & & \\
\hline \multirow[t]{12}{*}{4} & Intuitive & Causal & Pre- & 72 & 3.60 & 0.55 & 1.95 \\
\hline & & & Post- & 72 & 3.42 & 0.96 & \\
\hline & & Descriptive & Pre- & 72 & 3.60 & 0.55 & $4.26^{* * *}$ \\
\hline & & & Post- & 72 & 3.21 & 0.99 & \\
\hline & & Circular & Pre- & 72 & 3.60 & 0.55 & $3.29^{* *}$ \\
\hline & & & Post- & 72 & 3.32 & 0.84 & \\
\hline & Counterintuitive & Causal & Pre- & 72 & 2.04 & 1.16 & $-4.26^{* * *}$ \\
\hline & & & Post- & 72 & 2.57 & 1.21 & \\
\hline & & Descriptive & Pre- & 72 & 2.04 & 1.16 & $-2.36^{*}$ \\
\hline & & & Post- & 72 & 2.31 & 1.36 & \\
\hline & & Circular & Pre- & 72 & 2.04 & 1.16 & -1.18 \\
\hline & & & Post- & 72 & 2.18 & 1.39 & \\
\hline \multirow[t]{12}{*}{5} & Intuitive & Causal & Pre- & 86 & 3.71 & 0.40 & $3.51^{* *}$ \\
\hline & & & Post- & 86 & 3.41 & 0.82 & \\
\hline & & Descriptive & Pre- & 86 & 3.71 & 0.40 & 1.83 \\
\hline & & & Post- & 86 & 3.58 & 0.68 & \\
\hline & & Circular & Pre- & 86 & 3.71 & 0.40 & 0.74 \\
\hline & & & Post- & 86 & 3.66 & 0.64 & \\
\hline & Counterintuitive & Causal & Pre- & 86 & 1.35 & 1.11 & $-4.96^{* * *}$ \\
\hline & & & Post- & 86 & 1.95 & 1.34 & \\
\hline & & Descriptive & Pre- & 86 & 1.35 & 1.11 & $-2.68^{* *}$ \\
\hline & & & Post- & 86 & 1.63 & 1.42 & \\
\hline & & Circular & Pre- & 86 & 1.35 & 1.11 & $-3.45^{* *}$ \\
\hline & & & Post- & 86 & 1.74 & 1.43 & \\
\hline
\end{tabular}

${ }^{*} p<.05 .{ }^{* *} p<.01 .{ }^{* * *} p<.001$.

과도 유의하게 나타나 $(F=5.69, d f=1,156, p<.01)$ 단순주효 과를 구체적으로 알아보고자 사후검정으로 Bonferroni 다중비 교를 실시하였다. Table 12를 통해 확인할 수 있듯이, 직관부합 정보 조건에서는 설명 후 유아의 정보 평가가 설명의 유형에 따라 다르지 않았다. 반면, 직관비부합 정보 조건에서 설명 후 유아의 정보 평가는 추가된 설명이 인과적 설명인 경우 2.23 점 $(S D=1.32)$, 묘사적 설명인 경우 1.94 점 $(S D=1.43)$, 순환적 설명인 경우 1.94 점 $(S D=1.42)$ 으로 설명의 유형 조건 간 유의 한 차이가 있었다 $(F=8.26 p<.01)$. 이 결과는 Table 10 에서 확 인된 설명의 유형이 가지는 주효과를 더 세부적으로 살펴볼 때 실제로 설명의 유형에 따른 차이가 직관비부합 조건에서만 나타난다는 점을 보여준다. 그리고 유아가 직관비부합 정보에 인과적 설명을 제공 받으면 묘사적 설명이나 순환적 설명을 받는 경우에 비해 정보가 타당하다는 평가를 더 많이 함을 의
미한다. 즉, 유아는 정보를 평가할 때 정보가 직관에 부합하지 않는 경우에서 주로 설명의 유형에 민감성을 보이며, 세부적 으로 인과적 설명이 추가될 때 상대적으로 정보를 더 타당하 다고 평가하는 경향을 보임을 확인하였다.

\section{설명 전과 후 유아의 정보 평가}

정보에 대한 부연으로 설명이 제공됨에 따라 유아의 정보 평 가가 어떻게 달라지는지를 살펴보기 위해 두 번의 정보 평 가의 차이를 대응표본 $t$-검증을 통해 확인하였고, 그 결과는 Table 13에 제시하였다. 유아의 설명 전후의 평가 차이는 직관 부합 정보 조건과 직관비부합 정보 조건별로 각각 유사한 양 상을 보였다. 설명이 추가된 이후 유아의 직관부합 정보에 대 한 평가는 설명 전에 비해 대체로 낮아지는 경향을 보였고, 구 
체적으로는 4세 유아의 경우에 묘사적 설명 제공 시 $(t=4.26$, $p<.001)$, 순환적 설명 시 $(t=3.29, p<.01)$, 그리고 5세 유아의 경우에 인과적 설명 제공 시 $(t=-4.26, p<.001)$ 에 각각 유의 한 수준으로 낮아졌다. 반면에, 설명이 추가된 이후 유아의 직 관비부합 정보에 대한 평가는 설명 전에 비해 대체로 높아지 는 경향을 보였고, 4 세 유아의 경우에 인과적 설명 제공 시 $(t=$ $-4.26, p<.001)$, 묘사적 설명 시 $(t=-2.36, p<.05)$, 그리고 5세 유아의 경우에 인과적 설명 제공 시 $(t=-4.96, p<.001)$, 묘사적 설명 시 $(t=-2.68, p<.01)$, 순환적 설명 시 $(t=-3.45, p<.01)$ 에 각각 유의한 수준으로 높아졌다. 이 결과는 유아가 정보를 그 럴듯하다고 보는 정도가 부연 설명이 제공되는지 여부에 따라 달라짐을 보여준다. 특히, 직관에 부합하지 않는 정보에 덧붙 여진 설명은 대체로 유아가 정보를 더 그럴듯하다고 여기도록 지지해주는 역할을 하는 반면 직관에 부합하는 정보에 부가된 설명은 오히려 유아가 설명 전에 정보의 타당성을 상당히 허 용적인 수준으로 인정했던 경향을 다소 낮추는 역할을 한다는 점을 확인할 수 있었다.

\section{Discussion}

타인이 구두로 전달한 정보를 살피고 평가하는 유아의 능력에 대한 학자들의 관심이 높아지는 시점에서, 이 연구는 유아가 비교 정보 없이 단독으로 제공된 정보의 그럴듯함을 스스로 평가할 수 있는지, 한다면 어떤 단서를 활용하는지를 증명하 는 연구가 부족하다는 점에 주목하였다. 또한 유아가 추후 일 반화된 지식으로 습득될 가능성이 있는 물리.생물 현상에 대 한 정보를 평가하는 과정을 밝히고, 정보의 그럴듯함을 인식 적인 수준에서 탐색하는 과정이 유아의 인지발달에 어떤 함의 를 가지는지를 확인하고자 하였다. 이러한 목적에 따라 서울 및 경기도 소재 어린이집에서 4세 유아 72 명, 5세 유아 86명, 총 158 명을 연구대상으로 하여 정보의 직관부합성, 설명 유형 및 여부, 연령에 따라 유아의 정보 평가에 차이가 있는지를 확 인해보았다. 분석의 결과를 토대로 논의하고 결론을 내리면 다음과 같다.

첫째, 타인이 전달하는 물리.생물 현상 정보를 들은 후 유 아는 정보가 직관에 부합하는지 여부를 단서로 정보를 평가 한다. 그리고 유아는 직관에 부합하는 정보를 직관에 부합하 지 않는 정보에 비해 더 타당하다고 평가하며, 이 양상은 연령 에 따라 다르지 않다. 주변의 다양한 대상과 현상을 자신이 가 진 초보적인 수준의 신념에 기초하여 바라보고 이해하는 것은
유아기 대표적인 특성이다(Piaget, 1929; Wellman \& Gelman, 1998). 위 결과는 3 세경의 유아가 대상의 명칭과 같은 간단 한 정보가 두 명의 정보제공자에 의해 각각 제공될 때 그 정보 들이 사전지식과 일치하는지 혹은 어긋나는지에 따라 두 명 의 정보제공자의 신뢰성을 분별한다는 점을 확인한 연구들 (Jaswal \& Neely, 2006; Koenig, Clément, \& Harris, 2004; Koenig \& Harris, 2005), 그리고 두 가지 범주가 혼합된 외적 특성을 가 지는 물체의 명칭에 대한 정보가 있을 때 6세경의 유아가 대 상의 범주에 대한 자신의 직관에 그 정보가 어느 정도로 부합 하는지에 따라 범주 추리를 다르게 한다는 점을 보여준 연구 (Chan \& Tardif, 2013)와 유사성을 가진다. 본 연구는 정보의 범위를 넓혀 유아가 물리.생물 현상의 정보를 단독으로 들었 을 때에도 그 정보가 자신의 직관에 부합하는지 그 여부에 따 라 유아가 정보에 대해 다른 평가를 내린다는 점을 보여준다. 특히 타인이 전달한 정보가 유아의 직관에 부합하는지가 정보 의 타당성에 초점을 둔 평가에 하나의 단서로 활용된다는 점 을 제시한 입장(Bascandziev \& Harris, 2016; Harris et al., 2018) 을 경험적으로 입증한다.

또한 4-5세 유아는 직관에 부합하는 정보의 타당성에 대해 유사한 평가를 하나, 직관에 부합하지 않는 정보에 대해서는 5 세가 4세에 비해 정보가 타당하다는 평가를 더 적게 한다. 즉, 유아는 직관에 부합하는 정보에 비해 직관에 부합하지 않는 정 보를 타당하다고 평가하는 경우가 더 적고, 직관에 부합하지 않는 정보를 타당하다고 평가하는 경향은 연령의 증가에 따 라 더 약해진다. 이는 상위연령으로 갈수록 자신의 직관에 부 합하지 않는 정보가 사실일 가능성에 더 회의적이 됨을 의미한 다. 이 결과는 3-4세경의 유아가 물리·생물 현상과 관련한 기 대에 강하게 어긋나는 사건과 일상적인 사건의 실현 가능성 을 묻는 질문에 서로 다른 판단을 보인다는 점을 밝힌 선행연 구들(Browne \& Woolley, 2004; Kalish, 1998; Schult \& Wellman, 1997; Shtulman \& Carey, 2007), 그리고 4세 이상의 유아가 타 인이 말한 물리·생물 현상이 직관에 부합하는지 아닌지에 따 라 그 현상의 실현 가능성을 차별적으로 평가함을 보여준 Lane 과 Harris (2015)의 연구 결과와 유사하다. 사실 유아는 정보제 공자의 생각과 주장을 담은 정보가 사회적 의사소통을 통해 직 접 전달될 때 이것에 특히 높은 신뢰를 보인다(Heyman, 2008; Jaswal \& Kondrad, 2016). 그럼에도 본 연구는 정보제공자가 정 보를 직접 전달한 경우에서도 4 세 유아가 이 정보를 하나의 평 가 대상으로 놓고 그것이 그럴듯한지를 합리적으로 살피는 평 가를 한다는 점을 밝혔다는 차별성을 가진다.

둘째, 정보에 설명이 추가되면 유아는 설명의 유형도 단서 
로 활용하여 정보를 평가한다. 특히 직관에 부합하지 않는 정 보가 제공된 경우에 어떤 유형의 설명이 추가되는지에 따라 유아는 정보 평가를 다르게 한다. 직관에 부합하지 않는 정보 에 인과적 설명이 더해지면, 유아는 묘사적 설명이나 순환적 설명이 더해질 때에 비해 정보가 타당하다고 평가하는 경향을 더 많이 보인다.

추가 설명이 제공된 상황에서 정보의 직관부합성에 따라 유아가 정보의 타당성을 평가하는 양상은 설명 전에 비해 크 게 달라지지 않으며, 이는 정보가 직관에 부합하는지 여부가 유아의 정보 타당성 평가에 우선적이고 우세하게 작용하는 단 서임을 확인해준다. 그러나 설명의 유형은 유아가 직관에 부 합하지 않는 정보를 평가하는 구체적인 양상에 영향을 미친 다. 즉, 유아는 직관에 부합하지 않는 정보의 타당성을 비교적 낮게 보지만 다른 유형의 설명과 비교할 때 인과적 설명이 추 가되면 정보의 타당성에 대해 향상된 인식을 보인다. 이러한 결과는 유아가 잘 모르거나 의아한 정보를 접할 때 무지함이 나 혼동의 상태를 해결해줄 인과적 설명에 대한 선호를 보이 고 이를 빈번히 요구한다(Chouinard, 2007; Frazier et al., 2016; Kurkul \& Corriveau, 2018)는 점을 밝힌 기존 연구들과 일관성 을 가진다. 이미 가진 신념에 어긋나는 자극은 특히 유아에게 탐구에 대한 동기를 적극 불러일으킨다(Legare, 2012; Legare, Gelman, \& Wellman, 2010). 마찬가지로 유아는 지적인 의문을 일으키는 물리.생물 현상 정보를 들었을 때, 발생요인이나 원 리 등에 기초하여 현상의 임의성을 낮추고 필연성을 높여주는 인과적 설명을 통해 설득을 얻는 것으로 보인다.

그동안 설명의 질에 대한 4-5세 유아의 인식 발달을 다룬 연구들은 간단한 질문에 대한 답으로 제공되는 설명이 있을 때 문장 형식의 순환성과 같은 특성에 기초하여 그 안에 질문 에 대한 답이 담겨 있는지 여부를 구분해내는지에 초점을 두 었다(Corriveau \& Kurkul, 2014; Mercier et al., 2014). 그러나 정 보를 보완하기 위해 추가되는 설명을 정보의 내용과 연관 지 어 살피고 이를 토대로 정보의 타당성에 대해 차별적인 평가 를 내리는 일은 더 복합적이고 논리적인 사고를 요구하는 과 정일 수 있다. 따라서 본 연구의 결과는 기존의 연구들과는 또 다른 관점에서 유아기 중후반에 나타나는 설명의 특성에 대한 민감성을 증명해준다. 또한 누군가의 주장으로 제공된 불확실 한 정보가 있을 때 이를 뒷받침하기 위해 덧붙는 근거의 유무 나 그 유형을 정보의 타당성 평가에 활용하는 경향이 유아기 동안 발달적 변화를 보인다는 점을 확인시켜준다.

셋째, 정보의 부연인 설명이 제공되는지 여부는 유아의 정 보 평가에 차이를 가져오며, 즉 유아는 설명을 듣고 난 후 정보
가 그럴듯한지를 이전과 다르게 평가한다. 구체적으로, 설명 을 들은 후에 4-5세 유아는 대체로 직관에 부합하는 정보를 설 명 전에 비해 덜 타당하다고 평가하는 경향을 보이며, 직관에 부합하지 않는 정보는 설명 전에 비해 더 타당하다고 평가하 는 경향을 보인다. 이는 유아가 정보와 그것을 보완하기 위해 제공된 설명이 있을 때 정보가 그럴듯한지를 종합적으로 검토 하는 과정에 관여한다는 점을 제시한다. 특히 이 때 평가는 하 나의 주제를 가지고 전달되는 정보와 설명의 총체에 대한 평 가라는 점에서 의미가 있다.

본 연구의 결과는 정보가 직관에 부합하는지 여부와 설명 의 유형 및 여부가 유아의 정보 평가에 주요한 단서가 된다는 점을 보임과 동시에 직관에 부합하지 않는 정보의 평가와 설 명 유형 및 여부에 따른 정보 평가에 있어 발달적 차이가 존재 함을 보인다. 먼저 유아가 직관에 부합하는 정보의 타당성을 강하게 인정하는 양상과 비교할 때 직관에 부합하지 않는 정 보의 타당성을 인정하지 않는 경향은 그 정도로 강하지 않으 며, 즉 직관에 부합하지 않는 정보를 종종 타당하다고 본다. 그 러나 연령의 증가에 따라 직관에 부합하지 않는 정보의 타당 성을 인정하는 데 점점 엄격해진다. 경우에 따라 혹은 연령의 증가에 따라 직관에 부합하지 않는 정보에 대한 평가가 달라 진다는 점은 직관이 유아의 평가를 완전히 제약하는 것은 아 님을 의미한다. 특히 연령이 높아짐에 따라 그 제약의 강도가 변화한다. 또한 유아는 정보와 함께 외부에서 들어온 설명과 그 유형을 살피는 방법으로 정보 평가에 관여한다는 점을 확 인하였다. 평가에 두 번 관여하게 하는 과제수행절차와 관련 한 생태학적 효과나 직관에 부합하는 정보의 타당성에 대한 유아의 첫 평가가 천장효과를 보이는 것과 같이 꽤 높은 수준 이었다는 점을 일부 고려해야 하겠지만, 유아는 직관에 부합 하지 않는 정보가 아니라 익숙하고 자연스럽게 들리는 정보에 도 경계심을 높이고 특히 4세와 달리 5세 유아는 직관에 부합 하는 정보에 인과적 설명이 추가될 때 경계심을 더 올린다.

위의 결과들은 타인이 제공한 정보를 자신의 지식으로 받 아들이거나 거부하거나 혹은 수정된 형태로 습득하는 데 있어 중간 사고 단계인 정보에 대한 평가가 유아기 동안에 발달적 변화를 보인다는 점을 보여준다. 실제로 유아는 성장하며 직 관 이외에도 다양한 사전지식과 경험을 축적해나간다. 이 때 유아가 현재 가지고 있는 지식구조는 경험을 통해 반복적으 로 수정되고 새롭게 형성되며 질적인 변화를 겪는다(Gopnik \& Meltzoff, 1997). 타인으로부터 정보와 그에 대한 부연 설명 이 유아에게 전달되고 이해될 때 그 내용들과 관련하여 유아 가 이미 가지고 있는 자원으로써 직관, 신념과 사전지식들이 
함께 활성화된다(Sperber \& Wilson, 1995). 높은 연령의 유아가 정보를 인지적으로 탐색하는 과정에 활용할 자원들을 상대적 으로 더 많이 가지며 물리.생물 현상에 대한 이해 수준도 비교 적 높을 것으로 예상된다. 또한 외부에서 정보와 설명이 들어 올 때 자신이 가진 자원들과의 관련성을 떠올리고 정보가 사 실인지에 대한 근거를 적극적으로 찾는 과정은 직관에 기초한 사고 그 이상을 필요로 한다. 기본값과 같이 존재하는 개인의 직관적 사고는 고차원적이지 않고 편견이나 오류를 만들 가능 성을 가지지만, 이미 관련 경험이나 지식들을 가지고 있는 경 우에서 나름의 효율성을 가진다(Berry \& Dienes, 1993; Evans, 2010; Gigerenzer, 2007). 이와 비교하여 인식적인 수준에서 본 격적으로 이루어지는 정보 평가는 직관적 사고를 넘어 반영적 사고에 토대를 두며(Mercier \& Sperber, 2009), 시간과 노력이 더 들더라도 그 정확성이 더 높을 수 있다. 다행히 유아기 동안 일반적인 추론능력과 뇌의 인지기능이 계속 향상된다(Best \& Miller, 2010; Gopnik \& Schulz, 2007; Mercier, 2011)는 점은 긍 정적이다. 연령의 증가에 따라 추론에 의한 반영적 사고가 강 화됨에 따라 유아가 정보의 단서를 민감하게 해석하고 정보의 타당성을 복합적으로 살피는 과정이 전반적으로 더 원활해질 것으로 추측된다. 유아가 직관적인 수준을 넘어 의식적인 수 준에서 정보의 타당성을 의심하고 살피는 과정에 관여하는 일 은 노출된 정보를 무분별하게 받아들일 가능성을 낮추고 좋은 정보의 선별을 통해 인지적으로 한 단계 성장해나가는 데 기 여할 수 있을 것이다.

본 연구에서는 유아가 타인에 의해 제공된 정보 그 자체 에 대한 평가를 할 수 있는지에 초점을 두고, 그 가능성을 분 명히 확인하였다. 이와는 별개로, 그동안의 다른 연구들은 정 보제공자가 이전상황에서 보여준 정확성이나 그들의 전문 성, 선의, 친숙성, 힘, 매력 등과 같은 정보제공자의 특성에 따 라 유아가 정보에 대한 신뢰를 달리 보인다는 점을 밝혀왔다

(Bascandziev \& Harris, 2016; Castelain, Bernard, Van der Henst, \& Mercier, 2016; Corriveau \& Harris, 2009; Harris \& Corriveau, 2011; Koenig \& Harris, 2005; Landrum, Mills, \& Johnston, 2013). 또한 유아가 정보의 내용 뿐 아니라 정보제공자의 확신, 정보 의 출처 혹은 확실성 등을 암시하는 전달 형식인 연결사나 문 미 형태소 등의 문법 요소에 대해서도 민감성을 보인다는 점 을 제시하기도 하였다(Bernard, Mercier, \& Clément, 2012; Y. O. Choi, Jang, \& Lee, 2012; Y. O. Choi, Lee, \& Jang, 2010). 연령의 증가에 따라 폭넓은 의사소통 경험의 축적으로 사회인지 능력 이 발달되고 언어 표현의 미묘한 차이에 대한 이해가 향상되 어갈 때, 정보의 내용과 세부적인 표현, 그리고 정보제공자의
특성과 기타 상황적 요인들 등을 통합적으로 고려하며 타인이 전달한 구두 정보를 더욱 객관적으로 평가하게 될 수 있을 것 이라 예상된다(Mills, 2013). 특히 친숙하고 신뢰할 수 있는 대 상이 전달하는 정보도 항상 맞는 것은 아니며 여러 이유로 정 보의 사실성 여부나 질이 때에 따라 다를 수 있다는 신념이 형 성되면 정보 자체가 타당한지에 초점을 둔 평가가 집중적으로 이루어질 수 있을 것이다. 앞으로 유아의 정보 평가를 인지발 달의 관점에서 뿐 아니라 사회인지 발달 및 언어 발달과 관련 하여 유기적으로 설명해줄 관점의 필요성이 제기된다.

위와 같은 결론을 제시하는 이 연구는 다음의 의의를 가진 다. 먼저, 이 연구는 유아가 정보가 그럴듯한지를 스스로 가늠 할 때 정보가 직관에 부합하는지 여부와 정보의 주장성이 얼 마나 강한지가 단서로 활용된다는 점을 제시한 학자들의 입장 (Bascandziev \& Harris, 2016; Harris et al., 2018)을 물리.생물영 역의 정보를 중심으로, 국내 유아를 대상으로 검증하였다는 데 의의를 가진다. 또한 4-5세 유아가 정보가 직관에 부합하는 지 여부와 설명 유형 및 여부를 토대로 타인이 제공한 물리·생 물 현상 정보에 대해 평가할 때, 연령에 따른 발달적 변화가 존 재함을 확인하였다. 따라서 이 연구는 전달된 정보에 유의하 고 이를 평가하는 유아의 능력이 정보에 대한 선별과 그에 따 른 지식구조의 수정으로 이어져 인지발달에 기여한다고 보는 연구자들의 관점(Harris et al., 2018; Sperber et al., 2010)에 지지 를 제공하였다. 그리고 유아기 후반에 이르는 정보 평가의 과 정에 초점을 두고 초기 탐색적.비판적 사고 발달에 대한 이해 를 제공하였다.

이에 따라 본 연구는 유아가 타인이 전달한 정보를 다양한 관점에서 살필 수 있도록 질문을 하고 추론을 격려하는 방법 으로 일방적인 정보 전달이 아닌 상호 반응적인 정보 교류를 해야 한다는 실천적 함의를 제공한다. 더불어 성인이 정보에 이어 곧바로 설명을 제공하는 일이 빠르고 직접적인 설득 효 과를 가질 수 있다는 점에도 유의하고, 유아가 기존의 신념이 나 지식에 부합하거나 부합하지 않는 정보, 그리고 이를 뒷받 침하는 설명에 모두 경계심을 가지면서도 새로운 가능성을 열 어두도록 도울 필요가 있을 것이다. 무엇보다 유아가 필요한 정보과 설명을 스스로 찾아나가는 능력과 그것을 합리적으로 평가하여 이를 토대로 좋은 정보를 취하는 능력을 길러 지식 의 습득과 인지발달의 토대로 삼도록 지원해야 할 것이다.

마지막으로 본 연구의 제한점을 제시하고 후속연구를 위한 제언을 한다면 다음과 같다. 연구목적에 따라 마련된 정보와 설명이 타당하게 구성되었는지를 단계적으로 검토하였지만, 문장에 포함된 구체적인 표현이 가지는 특성이나 각 문장에 
대한 개별 유아의 해석과 반응이 결과에 영향을 미쳤을 가능 성도 일부 존재할 수 있다. 또한 유아에게 어린이집은 교사로 부터 안내받고 배움을 얻는 장소로 인식될 수 있다는 점에서 연구가 이루어진 장소인 어린이집의 특성이 과제 상황에서 정 보에 대한 유아의 전반적인 신뢰 수준에 영향을 미쳤을 가능 성도 있을 것이다. 더불어 본 연구에서는 연령 이외에 정보 평 가에 관련될 수 있는 기질, 언어능력, 지능과 같은 개인 특성이 나 기타 상황적 요인에 대한 논의를 포함하지 않았다. 본 연구 결과의 일반화 가능성을 높여줄 유사 주제의 연구들이 이어져 유아가 정보의 그럴듯함을 평가하는 데 단서로 활용하는 또 다른 정보의 특성이나 개인차와 연령차를 밝혀줄 결과들이 축 적되고, 유아의 정보 평가에 대해 더 체계적이고 통합적인 설 명을 제공할 수 있길 기대한다.

\section{Notes}

This article is a part of the first author's doctoral dissertation submitted in 2019.

\section{Conflict of Interest}

No potential conflict of interest relevant to this article was reported.

\section{Ethics Statement}

All procedures of this research were reviewed by IRB (1811/003013).

\section{References}

\section{In English}

Baillargeon, R. (1986). Representing the existence and the location of hidden objects: Object permanence in 6- and 8-monthold infants. Cognition, 23(1), 21-41. doi:10.1016/00100277(86)90052-1

Baillargeon, R. (1994). How do infants learn about the physical world? Current Directions in Psychological Science, 3(5), 133-
140. doi:10.1111/1467-8721.ep10770614

Bascandziev, I., \& Harris, P. L. (2016). The beautiful and the accurate: Are children's selective trust decisions biased? Journal of Experimental Child Psychology, 152, 92-105. doi:10.1016/j.jecp.2016.06.017

Baum, L. A., Danovitch, J. H., \& Keil, F. C. (2008). Children's sensitivity to circular explanations. Journal of Experimental Child Psychology, 100(2), 146-155. doi:10.1016/j.jecp.2007. 10.007

Bernard, S., Mercier, H., \& Clément, F. (2012). The power of wellconnected arguments: Early sensitivity to the connective because. Journal of Experimental Child Psychology, 111(1), 128-135. doi:10.1016/j.jecp.2011.07.003

Berry, D. C., \& Dienes, Z. (1993). Implicit learning: Theoretical and empirical issues. East Sussex, UK: Lawrence Erlbaum Associates.

Best, J. R., \& Miller, P. H. (2010). A developmental perspective on executive function. Child Development, 81(6), 1641-1660. doi:10.1111/j.1467-8624.2010.01499.x

Bohannon, J. N., \& Bonvillian, J. D. (1997). Theoretical approaches to language acquisition. In J. B. Gleason (Ed.), The development of language (4th ed., pp. 259-316). Boston, MA: Allyn and Bacon.

Brewer, W. F., Chinn, C. A., \& Samarapungavan, A. (1998). Explanation in scientists and children. Minds and Machines, 8(1), 119-136. doi:10.1023/A:1008242619231

Browne, C. A., \& Woolley, J. D. (2004). Preschoolers' magical explanations for violations of physical, social, and mental laws. Journal of Cognition and Development, 5(2), 239-260. doi:10.1207/s15327647jcd0502_4

Carey, S. (1985). Conceptual change in childhood. Cambridge, MA: MIT Press.

Castelain, T., Bernard, S., Van der Henst, J.-B., \& Mercier, H. (2016). The influence of power and reason on young Maya children's endorsement of testimony. Developmental Science, 19(6), 957-966. doi:10.1111/desc.12336

Chan, C. C. Y., \& Tardif, T. (2013). Knowing better: The role of prior knowledge and culture in trust in testimony. Developmental Psychology, 49(3), 591-601. doi:10.1037/a0031336

Chouinard, M. M. (2007). Children's questions: A mechanism for cognitive development. Monographs of the Society for Research in Child Development, 72(1), 1-129.

Corriveau, K., \& Harris, P. L. (2009). Choosing your informant: Weighing familiarity and recent accuracy. Developmental Science, 12(3), 426-437. doi:10.1111/j.1467-7687.2008.00792.x

Corriveau, K., \& Kurkul, K. E. (2014). "Why does rain fall?": Children prefer to learn from an informant who uses noncircular explanations. Child Development, 85(5), $1827-$ 1835. doi: $10.1111 /$ cdev. 12240

Couillard, N. L., \& Woodward, A. L. (1999). Children's 
comprehension of deceptive points. British Journal of Developmental Psychology, 17(4), 515-521. doi:10.1348/ 026151099165447

Dawkins, R., \& Krebs, J. R. (1978). Animal signals: Information or manipulation? In J. R. Krebs \& N. B. Davies (Eds.), Behavioural ecology: An evolutionary approach (pp. 282309). Oxford, UK: Blackwell Scientific Publications.

Epstein, S. (1994). Integration of the cognitive and psychodynamic unconscious. American Psychologist, 49(8), 709-724.

Evans, J. St. B. T. (2008). Dual-processing accounts of reasoning, judgment, and social cognition. Annual Review of Psychology, 59, 255-278. doi:10.1146/annurev.psych.59.103006.093629

Evans, J. St. B. T. (2010). Intuition and reasoning: A dual-process perspective. Psychological Inquiry, 21(4), 313-326. doi:10.1 080/1047840X.2010.521057

Evans, J. St. B. T. (2011). Dual-process theories of reasoning: Contemporary issues and developmental applications. Developmental Review, 31(2-3), 86-102. doi:10.1016/ j.dr.2011.07.007

Frazier, B. N., Gelman, S. A., \& Wellman, H. M. (2009). Preschoolers' search for explanatory information within adult-child conversation. Child Development, 80(6), 15921611. doi:10.1111/j.1467-8624.2009.01356.x

Frazier, B. N., Gelman, S. A., \& Wellman, H. M. (2016). Young children prefer and remember satisfying explanations. Journal of Cognition and Development, 17(5), 718-736. doi: 10.1080/15248372.2015.1098649

Gelman, R. (2000). Domain specificity and variability in cognitive development. Child Development, 71(4), 854-856. doi:10.1111/1467-8624.00193

Gelman, R., Spelke, E. S., \& Meck, E. (1983). What preschoolers know about animate and inanimate objects. In D. Rogers $\&$ J. A. Sloboda (Eds.) The acquisition of symbolic skills (pp. 297-326). New York: Plenum Press.

Gigerenzer, G. (2007). Gut feelings: The intelligence of the unconscious. New York: Penguin Books.

Gopnik, A., \& Meltzoff, A. N. (1997). Words, thoughts, and theories. Cambridge, MA: MIT Press.

Gopnik, A., \& Schulz, L. (2007). Causal learning: Psychology, philosophy, and computation. Oxford, UK: Oxford University Press.

Haden, C. A., Reese, E., \& Fivush, R. (1996). Mother's extratextual comments during storybook reading: Stylistic differences over time and across tests. Discourse Processes, 21(2), 135-169. doi:10.1080/01638539609544953

Harris, P. L. (2012). Trusting what you're told: How children learn from others. Cambridge, MA: Harvard University Press.

Harris, P. L., \& Corriveau, K. (2011). Young children's selective trust in informants. Philosophical Transactions of the Royal Society B, 366(1567), 1179-1187. doi:10.1098/ rstb.2010.0321

Harris, P. L., Koenig, M. A., Corriveau, K., \& Jaswal, V. K. (2018). Cognitive foundations of learning from testimony. Annual Review of Psychology, 69, 251-273. doi:10.1146/annurevpsych-122216-011710

Heyman, G. D. (2008). Children's critical thinking when learning from others. Current Directions in Psychological Science, 17(5), 344-347. doi:10.1111/j.1467-8721.2008.00603.x

Heyman, G. D., Fu, G., \& Lee, K. (2007). Evaluating claims people make about themselves: The development of skepticism. Child Development, 78(2), 367-375. doi:10.1111/j.14678624.2007.01003.x

Hogarth, R. M. (2001). Educating intuition. Chicago, IL: The University of Chicago Press.

Inagaki, K., \& Hatano, G. (1996). Young children's recognition of commonalities between animals and plants. Child Development, 67(6), 2823-2840. doi:10.1111/j.1467-8624.1996. tb01890.x

Inagaki, K., \& Hatano, G. (2006). Young children's conception of the biological world. Current Directions in Psychological Science, 15(4), 177-181. doi:10.1111/j.1467-8721.2006. 00431.x

Jaswal, V. K. (2004). Don't believe everything you hear: Preschoolers' sensitivity to speaker intent in category induction. Child Development, 75(6), 1871-1885. doi:10.1111/j.14678624.2004.00822.x

Jaswal, V. K. (2010). Believing what you're told: Young children's trust in unexpected testimony about the physical world. Cognitive Psychology, 61(3), 248-272. doi:10.1016/ j.cogpsych.2010.06.002

Jaswal, V. K., Croft, A. C., Setia, A. R., \& Cole, C. A. (2010). Young children have a specific, highly robust bias to trust testimony. Psychological Science, 21(10), 1541-1547. doi:10.1177/0956797610383438

Jaswal, V. K., \& Kondrad, R. L. (2016). Why children are not always epistemically vigilant: Cognitive limits and social considerations. Child Development Perspectives, 10(4), 240244. doi: $10.1111 /$ cdep. 12187

Jaswal, V. K., \& Neely, L. A. (2006). Adults don't always know best preschoolers use past reliability over age when learning new words. Psychological Science, 17(9), 757-758. doi:10.1111/ j.1467-9280.2006.01778.x

Johnson, C. N., \& Harris, P. L. (1994). Magic: Special but not excluded. British Journal of Developmental Psychology, 12(1), 35-51. doi:10.1111/j.2044-835X.1994.tb00617.x

Jones, S. S., Smith, L. B., \& Landau, B. (1991). Object properties and knowledge in early lexical learning. Child Development, 62(3), 499-516. doi:10.1111/j.1467-8624.1991.tb01547.x

Jung, C. G. (1971). Psychological types. Princeton, NJ: University of Princeton Press. 
Kalish, C. (1998). Reasons and causes: Children's understanding of conformity to social rules and physical laws. Child Development, 69(3), 706-720. doi:10.1111/j.1467-8624. 1998.tb06238.x

Keil, F. C. (1995). The growth of causal understandings of natural kinds. In D. Sperber, D. Premack, \& A. J. Premack (Eds.), Symposia of the Fyssen foundation. Causal cognition: A multidisciplinary debate (pp. 234-267). New York: Clarendon Press/Oxford University Press.

Keil, F. C. (2006). Explanation and understanding. Annual Review of Psychology, 57, 227-254. doi:10.1146/annurev.psych.57. 102904.190100

Koenig, M. A. (2012). Beyond semantic accuracy: Preschoolers evaluate a speaker's reasons. Child Development, 83(3), 1051-1063. doi:10.1111/j.1467-8624.2012.01742.x

Koenig, M. A., Clément, F., \& Harris, P. L. (2004). Trust in testimony: Children's use of true and false statements. Psychological Science, 15(10), 694-698. doi:10.1111/j.09567976.2004.00742.x

Koenig, M. A., \& Harris, P. L. (2005). Preschoolers mistrust ignorant and inaccurate speakers. Child Development, 76(6), 1261-1277. doi:10.1111/j.1467-8624.2005.00849.x

Kondrad, R. L., \& Jaswal, V. K. (2012). Explaining the errors away: Young children forgive understandable semantic mistakes. Cognitive Development, 27(2), 126-135. doi:10.1016/ j.cogdev.2011.11.001

Kurkul, K. E., \& Corriveau, K. H. (2018). Question, explanation, follow-up: A mechanism for learning from others? Child Development, 89(1), 280-294. doi:10.1111/cdev.12726

Landrum, A. R., Mills, C. M., \& Johnston, A. M. (2013). When do children trust the expert? Benevolence information influences children's trust more than expertise. Developmental Science, 16(4), 622-638. doi:10.1111/desc.12059

Lane, J. D., \& Harris, P. L. (2015). The roles of intuition and informants' expertise in children's epistemic trust. Child Development, 86(3), 919-926. doi:10.1111/cdev.12324

Legare, C. H. (2012). Exploring explanation: Explaining inconsistent evidence informs exploratory, hypothesistesting behavior in young children. Child Development, 83(1), 173-185. doi:10.1111/j.1467-8624.2011.01691.x

Legare, C. H., Gelman, S. A., \& Wellman, H. M. (2010). Inconsistency with prior knowledge triggers children's causal explanatory reasoning. Child Development, 81(3), 929-944. doi:10.1111/j.1467-8624.2010.01443.x

Lombrozo, T. (2006). The structure and function of explanations. Trends in Cognitive Sciences, 10(10), 464-470. doi:10.1016/ j.tics.2006.08.004

Mercier, H. (2011). Reasoning serves argumentation in children. Cognitive Development, 26(3), 177-191. doi:10.1016/ j.cogdev.2010.12.001
Mercier, H., Bernard, S., \& Clément, F. (2014). Early sensitivity to arguments: How preschoolers weight circular arguments. Journal of Experimental Child Psychology, 125, 102-109. doi:10.1016/j.jecp.2013.11.011

Mercier, H., \& Sperber, D. (2009). Intuitive and reflective inference. In J. St. B. T. Evans \& K. Frankish (Eds.), In two minds: Dual processes and beyond (pp. 149-170). New York: Oxford University Press.

Mills, C. M. (2013). Knowing when to doubt: Developing a critical stance when learning from others. Developmental Psychology, 49(3), 404-418. doi:10.1037/a0029500

Mills, C. M., Danovitch, J. H., Rowles, S. P., \& Campbell, I. L. (2017). Children's success at detecting circular explanations and their interest in future learning. Psychonomic Bulletin \& Review, 24(5), 1465-1477. doi:10.3758/s13423-016-1195-2

Mills, C. M., \& Elashi, F. B. (2014). Children's skepticism: Developmental and individual differences in children's ability to detect and explain distorted claims. Journal of Experimental Child Psychology, 124, 1-17. doi:10.1016/ j.jecp.2014.01.015

Nurmsoo, E., \& Robinson, E. J. (2009). Children's trust in previously inaccurate informants who were well or poorly informed: When past errors can be excused. Child Development, 80(1), 23-27. doi:10.1111/j.1467-8624.2008.01243.x

Pellegrini, A. D., Brody, G. H., \& Sigel, I. E. (1985). Parents' book-reading habits with their children. Journal of Educational Psychology, 77(3), 332-340. doi:10.1037/00220663.77.3.332

Piaget, J. (1929). The children's conception of the world. London: Routledge \& Kegan Paul.

Rosengren, K. S., Gelman, S. A., Kalish, C. W., \& McCormick, M. (1991). As time goes by: Children's early understanding of growth in animals. Child Development, 62(6), 1302-1320. doi:10.1111/j.1467-8624.1991.tb01607.x

Rosengren, K. S., \& Hickling, A. K. (1994). Seeing is believing: Children's explanations of commonplace, magical, and extraordinary transformations. Child Development, 65(6), 1605-1626. doi:10.1111/j.1467-8624.1994.tb00838.x

Schult, C. A., \& Wellman, H. M. (1997). Explaining human movements and actions: Children's understanding of the limits of psychological explanation. Cognition, 62(3), 291324. doi:10.1016/S0010-0277(96)00786-X

Shtulman, A. (2009). The development of possibility judgment within and across domains. Cognitive Development, 24(3), 293-309. doi:10.1016/j.cogdev.2008.12.006

Shtulman, A., \& Carey, S. (2007). Improbable or impossible? How children reason about the possibility of extraordinary events. Child Development, 78(3), 1015-1032. doi:10.1111/ j.1467-8624.2007.01047.x

Spelke, E. (1994). Initial knowledge: Six suggestions. Cognition, 
50(1-3), 431-445. doi:10.1016/0010-0277(94)90039-6

Spelke, E. (2000). Core knowledge. American Psychologist, 55(11), 1233-1243. doi:10.1037/0003-066X.55.11.1233

Spelke, E., Breinlinger, K., Macomber, J., \& Jacobson, K. (1992). Origins of knowledge. Psychological Review, 99(4), 605632. doi:10.1037/0033-295X.99.4.605

Sperber, D., Clément, F., Heintz, C., Mascaro, O., Mercier, H., Origgi, G., \& Wilson, D. (2010). Epistemic vigilance. Mind \& Language, 25(4), 359-393. doi:10.1111/j.14680017.2010.01394.x

Sperber, D., \& Wilson, D. (1995). Relevance: Communication \& cognition (2nd ed.). Oxford, UK: Blackwell Publishers.

Walker, C. M., Lombrozo, T., Williams, J. J., Rafferty, A. N., \& Gopnik, A. (2017). Explaining constrains causal learning in childhood. Child Development, 88(1), 229-246. doi:10.1111/cdev. 12590

Wellman, H. M., \& Gelman, S. A. (1998). Knowledge acquisition in foundational domains. In W. Damon (Ed.), Handbook of child psychology: Vol. 2. Cognition, perception, and language (pp. 523-573). Hoboken, NJ: John Wiley \& Sons.

Wellman, H. M., Hickling, A. K., \& Schult, C. A. (1997). Young children's psychological, physical, and biological explanations. New Directions for Child Development, 1997(75), 7-26. doi:10.1002/cd.23219977502

\section{In Korean}

Choi, S. J., \& Kwon, H. (2018). A study on interaction among children and their mother, father, and teacher in the process of reading picture books and children's reaction behavior. The Journal of Korea Open Association for Early Childhood Education, 23(4), 77-107. doi:10.20437/KOAECE23-4-04

Choi, Y. (2016). The development of selective trust and evidential reasoning: A literature review. The Korean Journal of Developmental Psychology, 29(1), 63-82.

Choi, Y., Jang, N.-Y., \& Lee, H.-I. (2012). Factors affecting Korean preschoolers' evidential reasoning: Trust in testimony and understanding of evidential marker. The Korean Journal of Developmental Psychology, 25(1), 135-152.

Choi, Y., Lee, H.-I., \& Jang, N.-Y. (2010). Development of understanding the relationship between information source and certainty. The Korean Journal of Developmental Psychology, 23(2), 109-124.

Gil, H.-J., \& Park, E.-H. (2013). The characteristics of dialogue between teacher and child during free play activity. The Journal of Korean Teacher Education, 30(2), 225-251.

Han, Y. J. (2000). Mother-child verbal interaction strategy in storybook reading and children's narrative competence (Doctoral dissertation). Retrieved from http://www.riss.kr/ link?id=T7861806

Pae, S., Lim, S., Lee, J., \& Chang, H. (2004). Gumunuimi ihaeryeok geomsa [구문의미 이해력 검사]. Seoul: Seoul Community Rehabilitation Center.

Sung, E.-Y., Kim, E.-S., \& Yoo, S.-H. (2011). Analysis of the verbal teaching behavior of early childhood teachers according to the age of children. Early Childhood Education Research \& Review, 15(1), 141-163.

Sung, M. Y., Chang, Y. E., \& Chang, M. S. (2016). Analysis on young children's mean length of utterance and type-token ratio by their gender and maternal conversational style. Korean Journal of Child Education and Care, 16(2), 119134. doi:10.21213/kjcec.2016.16.2.119

\section{ORCID}

Hye Ryung An http://orcid.org/0000-0001-7128-7297

Naya Choi http://orcid.org/0000-0001-9189-9370

Received July 31, 2019

Revision received August 13, 2019

Accepted August 15, 2019 